\title{
Epstein-Barr virus infection promotes Th1-mediated disease in a humanized immune mouse model
} of multiple sclerosis

Jessica R. Allanach ${ }^{1}$, Blair K. Hardman ${ }^{1 \dagger}$, Naomi M. Fettig ${ }^{1 \dagger}$, Vina Fan ${ }^{1}$, Ariel R. Rosen ${ }^{1}$, Iryna Shanina ${ }^{1}$, Galina Vorobeychik ${ }^{2,3}$, Lisa C. Osborne ${ }^{1}$, Marc S. Horwitz ${ }^{1 *}$

${ }^{1}$ Department of Microbiology and Immunology, The University of British Columbia, Vancouver BC, Canada

${ }^{2}$ Fraser Health Multiple Sclerosis Clinic, Burnaby BC, Canada

${ }^{3}$ Division of Neurology - Department of Medicine, University of British Columbia, Vancouver BC, Canada

$\dagger$ These authors contributed equally to this work

\section{* Corresponding:}

Marc S. Horwitz

Life Sciences Centre, Office 3551

2350 Health Sciences Mall

University of British Columbia

Vancouver, B. C., Canada V6T $1 Z 3$

604-822-6298

mhorwitz@mail.ubc.ca

Key terms: Humanized mice, peripheral blood mononuclear cell, Epstein-Barr virus infection, risk factor, multiple sclerosis, experimental autoimmune encephalomyelitis, T cell immunomodulation 


\begin{abstract}
Infection with the human-tropic Epstein-Barr virus (EBV) is a strong risk factor for multiple sclerosis (MS), though the underlying mechanisms remain unclear. To investigate EBV infection directly, we induced experimental autoimmune encephalomyelitis (EAE) in immunocompromised mice humanized with peripheral blood mononuclear cells (PBMCs) from individuals with or without a history of EBV infection and/or diagnosis of relapsing MS. HuPBMC EAE mice generated from EBV seronegative healthy donors (HD) were less susceptible to developing severe clinical symptoms than EBV seropositive cohorts. Donor EBV seropositivity and RRMS diagnosis led to a significant incremental increase in the human Th1:Treg $\mathrm{CD}^{+} \mathrm{T}$ cell ratio in the brain and spinal cord, as well as increased human cytotoxic $\mathrm{CD}^{+} \mathrm{T}$ cell and murine macrophage infiltration and demyelination. The data indicate that a history of EBV infection, further compounded by a diagnosis of RRMS, promotes Th1-mediated disease in a novel humanized mouse model of MS.
\end{abstract}




\section{BACKGROUND}

Multiple sclerosis (MS) is a neuroinflammatory disease of the central nervous system (CNS) characterized by infiltration of autoreactive lymphocytes, demyelination, and neurodegeneration ${ }^{1}$. Although the exact etiology of MS is unclear, development of the disease is thought to be a consequence of environmental triggers in genetically susceptible individuals ${ }^{2}$. The environmental factor most strongly and consistently linked to MS is infection with Epstein-Barr virus (EBV). EBV is a human gammaherpesvirus that latently infects memory B cells and which, while typically quiescent, is associated with a broad spectrum of malignancies and autoimmune disease ${ }^{3-5}$. Acute infection is usually asymptomatic when the virus is acquired at an early age, but delayed acquisition can cause infectious mononucleosis (IM); a self-limiting clinical condition marked by a large expansion of $\mathrm{CD}^{+} \mathrm{T}$ cells specific to viral antigens ${ }^{6}$. The connection between EBV infection and MS was first posited due to the prominent epidemiological overlap in cases of IM and $\mathrm{MS}^{7}$. Numerous studies have since provided evidence linking EBV infection with the development of $\mathrm{MS}^{8-13}$.

Individuals who are $\mathrm{EBV}$ seronegative $\left(\mathrm{EBV}^{-}\right)$have a relatively low risk for $\mathrm{MS}$, whereas asymptomatically infected individuals have a moderate risk, and those who have previously developed IM have a significantly higher risk for MS than those who acquired the virus asymptomatically ${ }^{8,14}$. Additionally, nearly all adult and pediatric MS patients are EBV seropositive $\left(\mathrm{EBV}^{+}\right)^{15-17}$, and $\mathrm{MS}$ patients show higher EBV-specific antibody titers than age-matched controls in the years preceding disease onset $^{10}$. MS patients also show increased frequencies of EBV-specific T cells in the blood compared to unaffected individuals with a similar viral load, some of which are cross reactive to myelin epitopes ${ }^{18,19}$. Recently, a longitudinal case-matched study demonstrated a 32-fold increased risk for MS and significant upregulation of a biomarker of axonal degeneration in individuals with MS, specifically following EBV seroconversion in young adulthood ${ }^{12}$. The efficacy of B cell depletion therapies in MS patients further suggests a role for EBV infection in disease, as anti-CD20 antibodies may target the viral reservoir ${ }^{20}$. Despite mounting epidemiological and clinical evidence suggesting EBV infection is a causative factor in MS, experimental investigation has been limited due to the high prevalence of EBV in the general population and, since EBV exclusively infects humans, a lack of suitable animal models.

EBV infection of immune system humanized mice has recapitulated various aspects of the viral immune response and pathogenesis of EBV-associated diseases observed in humans, including lytic and latent infections ${ }^{21,22}$, lymphoproliferation and tumor formation ${ }^{23-25}$, among others ${ }^{26,27}$. These humanized 
models, however, have not produced CNS-localized inflammation leading to motor deficits, as seen in classical experimental autoimmune encephalomyelitis (EAE) models of MS. We therefore induced EAE in humanized mice engrafted with peripheral blood mononuclear cells (PBMCs) based on the donor's EBV status and diagnosis of relapsing-remitting MS (RRMS) to directly evaluate the latent virus's role in disease development. Herein, we found that EBV status clearly defined the time of EAE onset and severity of disease, which was driven by altered regulatory and effector T cell infiltration of the CNS, indicating that latent EBV infection is a driving factor of CNS autoimmunity. 


\section{RESULTS}

\section{Donor EBV status and RRMS diagnosis influence clinical EAE outcomes in HuPBMC mice}

To evaluate the impact of EBV infection on clinical outcomes of disease in a humanized MS model, we engrafted NOD/SCID-IL2R $\gamma^{-/-}$(NSG) mice with PBMCs (HuPBMC mice) from three donor groups based on EBV seropositivity and RRMS diagnosis (Figure 1A). For this study, we enrolled treatment naïve female donors aged 19-39, due to the increased prevalence of RRMS among young women $^{28}$. Consistent with previous reports ${ }^{12,29}$, the donors diagnosed with RRMS were all EBV seropositive $\left(\mathrm{EBV}^{+}\right)$and exhibited significantly elevated $\mathrm{EBV}$-specific serum IgG titres to both the acute phase viral capsid antigen (VCA, Figure 1B) and the latent phase Epstein-Barr nuclear antigen 1 (EBNA1, Figure 1C) compared to previously infected, otherwise healthy $\mathrm{EBV}^{+}$donors. Uninfected $\mathrm{EBV}$ seronegative $\left(\mathrm{EBV}^{-}\right)$healthy donors (HDs) were identified and grouped based on the absence of serum IgM and IgG specific to both antigens. EBV viral load analysis of donor PBMCs confirmed that none of the donors had detectable levels of cell-associated EBV that might be indicative of a highly active infection or an EBV-associated disorder such as malignancy or infectious mononucleosis ${ }^{30}$ (Figure 1D). We also assessed donor group differences in other serological factors associated with MS. Our donors showed 33$50 \%$ seropositivity for cytomegalovirus (CMV) within each donor group, which reflects the general population $^{31,32}$. Although there was no significant difference in anti-CMV IgG titres between $\mathrm{EBV}^{+} \mathrm{HD}$ and the other two groups, RRMS EBV ${ }^{+}$donors had elevated anti-CMV IgG compared to EBV $\mathrm{HD}^{-}$(Figure S1A). We also verified that the donors did not have any overt seroreactivity to the inducing antigen, recombinant human myelin oligodendrocyte glycoprotein (rhMOG), and the donor groups had statistically similar serum 25-OH vitamin D levels (Figure S1B - C). Individual donor characteristics, including clinical MS parameters and viral serostatus, are reported in Table 1.

Flow cytometric analysis of transplanted PBMCs confirmed that recipient NSG mice were engrafted with a similar composition of immune cells from each donor (Figure S2, S3). HuPBMC mice were then induced with EAE using a mixture of rhMOG and $\mathrm{MOG}_{35-55}$ after a three-week reconstitution period (Figure 1A). HuPBMC mice were found to be susceptible to EAE and exhibited symptoms typical of other murine EAE models, including weight loss, piloerection, motor imbalance, and an ascending paralysis with resolution within approximately a week from onset. The development of paralysis was similar to the asynchronous, relapsing EAE phenotype of the Non-Obese Diabetic (NOD) background strain for the $\mathrm{NSG}^{33}$. HuPBMC EAE mice demonstrated an exacerbation of clinical disease by multiple 
measures when engrafted with PBMCs from donors who were $\mathrm{EBV}^{+}$and had been diagnosed with RRMS (Figure 1E - G). The overall disease course of EAE was significantly worsened in $\mathrm{EBV}^{+} \mathrm{HD}$ mice compared to $\mathrm{EBV}^{-} \mathrm{HD}$ mice, which was in turn significantly more severe in the $\mathrm{EBV}^{+} \mathrm{RRMS}$ recipient group compared to both HD groups (Figure 1E). The incidence of EAE symptoms was significantly greater in $\mathrm{EBV}^{+} \mathrm{RRMS}$ recipient mice compared to the HD groups, and moderately increased with EBV infection between HD groups (Figure 1F). HuPBMC EAE mice derived from $\mathrm{EBV}^{-} \mathrm{HD}$ donors also exhibited a significantly delayed time to symptom onset compared to the $\mathrm{EBV}^{+}$groups, which was not significantly different between the $\mathrm{EBV}^{+}$groups (Figure $1 \mathrm{G}$ ). The clinical outcomes of EAE indicate that donor EBV infection and RRMS diagnosis both increase disease susceptibility and severity in recipient HuPBMC EAE mice.

\section{Human $T$ cells infiltrate and localize to areas of demyelination in the CNS of HuPBMC EAE mice}

To investigate the underlying cause of the clinical disease differences associated with donor EBV and RRMS status, we evaluated the degree of demyelination of the spinal cord among the three recipient HuPBMC EAE groups. EAE induction of NOD mice and RRMS/HD EBV ${ }^{+} \mathrm{HuPBMC}$ mice led to a significant loss of myelin relative to unaffected NSG control mice (Figure 2A, S4A). EAE induction of $\mathrm{EBV}^{-} \mathrm{HD}$ recipient HuPBMC mice did not significantly reduce myelination of the spinal cord compared to NSG controls, suggesting greater protection from EAE consistent with diminished clinical disease severity in this group. As EAE is a predominantly a $\mathrm{T}$ cell-mediated disease ${ }^{34,35}$, we confirmed that engrafted human T cells could infiltrate the CNS following induction. Notably, we detected accumulation of human $\mathrm{CD}^{+} \mathrm{T}$ cells in the white matter of both the cerebellum (Figure 2B, S4B-C) and the spinal cord (Figure 2C) of HuPBMC EAE mice engrafted with RRMS donor PBMCs, indicating that engrafted human T cells can localize to demyelinated areas in the HuPBMC EAE model.

\section{CNS immunopathology in HuPBMC EAE is mediated by human Th1 and Te1 cells and murine macrophages}

In order to represent the majority of donors in any given population, we evaluated the immunopathological features of EAE in NSG mice engrafted with $\mathrm{HD} \mathrm{EBV}^{+}$PBMC. We characterized the phenotype of human T cells infiltrating the CNS to evaluate the pathogenicity of these cells in the HuPBMC EAE model. Consistent with our findings by histology, we observed substantial brain and spinal cord infiltration of both human $\mathrm{CD}^{+}\left(\mathrm{hCD}^{+}\right)$and $\mathrm{CD}^{+}\left(\mathrm{hCD}^{+}\right) \mathrm{T}$ cells by flow cytometry in HuPBMC 
EAE mice (Figure 3A). Interestingly, a considerable proportion of hCD4 ${ }^{+} \mathrm{T}$ cells in the CNS produced IFN $\gamma$, but very few expressed IL-17A, indicating that the model is predominantly Th1-driven (Figure 3A). Among CNS-infiltrating hCD8 ${ }^{+} \mathrm{T}$ cells, $\sim 65 \%$ expressed IFN $\gamma$ and/or Granzyme B (GzmB) (Figure 3A), suggesting they are capable of cytotoxic activity. Human T cell infiltration was detected in the CNS of all EAE-induced HuPBMC mice regardless of the development of clinically visible EAE symptoms (Figure S5). However, the spinal cords of mice that developed clinical symptoms contained significantly greater numbers of $\mathrm{hCD} 45^{+}$cells, including total $\mathrm{hCD}^{+}$and activated $\mathrm{hCD} 8^{+} \mathrm{T}$ cells, than mice that remained subclinical (Figure S5). Moreover, there was a significantly higher ratio of $\mathrm{hCD}^{+} \mathrm{T}$ cells relative to $\mathrm{hCD}^{+} \mathrm{T}$ cells in the CNS and spleens of mice with EAE symptoms (Figure 3B), suggesting a critical role for $\mathrm{hCD}^{+} \mathrm{T}$ cells in mediating demyelination sufficient to produce clinical deficits.

Myelin phagocytosis by infiltrating and resident macrophages/microglia is a key mediator of demyelination in EAE models ${ }^{36,37}$. In humanized mouse models, both endogenous murine and engrafted human myeloid cells reconstitute and can co-exist within the $\mathrm{CNS}^{38,39}$. We assessed the abundance of murine $\left(\mathrm{mCD} 45^{\mathrm{hi}} \mathrm{CD} 11 \mathrm{~b} \mathrm{~b}^{\mathrm{hi}} / 80^{+}\right)$and human $\left(\mathrm{hCD} 45^{+} \mathrm{CD} 14^{+} \mathrm{CD} 68^{+}\right)$macrophages in the $\mathrm{CNS}$ and periphery to determine the potential relative contribution of each subset to the immunopathology of HuPBMC EAE. Unlike hematopoietic stem cell engraftment-based humanized mouse models, PBMC humanization of NSG mice generally favors the engraftment of T cells over innate immune subsets ${ }^{40}$. We similarly observed numerous mCD45 ${ }^{\text {hi }}$ macrophages in the brains, spinal cords, and spleens of HuPBMC EAE mice but very few hCD $45^{+}$macrophages (Figure $3 \mathrm{C}$ ). The overall scarcity of hCD $45^{+} \mathrm{CD} 14^{+} \mathrm{CD} 68^{+}$ cells in the CNS suggests that infiltrating murine macrophages and resident microglia likely cooperate with cytotoxic human $\mathrm{T}$ cells to demyelinate axons. Indeed, we observed an increase in murine macrophage and microglia $\left(\mathrm{mCD} 45^{\text {lo }} \mathrm{CD} 11 \mathrm{~b}^{\text {hi }} \mathrm{F} 4 / 80^{+}\right)$numbers in the spinal cords of HuPBMC mice following EAE induction and a similar increasing trend in symptomatic EAE mice compared to subclinical mice derived from the same PBMC donor (Figure 3D, S6A). We further confirmed that murine myeloid cells phagocytosed myelin in the HuPBMC EAE model based on the detection of intracellular myelin basic protein (MBP) in macrophages/microglia in the CNS after induction $\left(26.4 \pm 15.7 \% \mathrm{MBP}^{+}\right.$in the CNS versus $2.13 \pm 2.88 \%$ in the spleen, mean $\pm \mathrm{SD}$ ) (Figure 3E, S6B). In the spinal cord, the total numbers of infiltrating $\mathrm{hCD}^{+} \mathrm{T}$ cells correlated strongly and specifically with the number of infiltrating $\mathrm{MBP}^{+}$ murine macrophages (Figure $3 \mathrm{~F}$ ); an association not observed with hCD4 ${ }^{+} \mathrm{T}$ cells or human macrophages (Figure S7). 
Collectively, the data indicate that infiltrating hCD4 ${ }^{+} \mathrm{T}$ cells direct a Th1 polarized response in the CNS of HuPBMC EAE mice that leads to $\mathrm{hCD}^{+} \mathrm{Tc1}$-mediated myelin damage and subsequent phagocytosis by murine macrophages and microglia. The capability of hCD $8^{+} \mathrm{T}$ cells to exert myelindirected cytotoxicity, however, was unclear in an interspecies model of immune-mediated demyelination. Based on previous work, which has demonstrated productive human T cell receptor (TCR) interactions with mouse major histocompatibility complex (MHC) in humanized NSG mice ${ }^{41}$, we assessed whether $\mathrm{hCD}^{+} \mathrm{T}$ cells could effectively interact with antigen presented on mouse MHC-expressing cells ex vivo (Figure 3G). Co-culture of sort-purified splenic $\mathrm{mCD} 45^{+}$and $\mathrm{hCD} 8^{+}$cells from HuPBMC mice in the presence of rhMOG resulted in a significant expansion of $\mathrm{mCD} 11 \mathrm{c}^{+}$cells, including those expressing CD40, and a simultaneous decrease in CD8 median fluorescence intensity (MFI) on human T cells (Figure $3 \mathrm{H})$, indicative of increased antigen recognition ${ }^{42}$. There was also a significant increase in the proportion of $\mathrm{hCD}^{+} \mathrm{T}$ cells expressing the antigen activation marker CD137, as well as IFN $\gamma$ (Figure $3 \mathrm{H}$ ), which affirms the functional capacity of $\mathrm{hCD}^{+} \mathrm{T}$ cells to recognize and respond to antigen in humanized mouse tissues. These data highlight the interspecies nature of the immunopathology of the HuPBMC EAE model and supports its use as a model of MS.

\section{Donor EBV infection and RRMS diagnosis impair regulatory $T$ cell accumulation in the CNS and promote Th1-mediated disease in HuPBMC EAE mice}

EBV intermittently reactivates from latently infected memory B cells to transmit to new cells ${ }^{3}$, which has been suggested to potentially contribute to relapses in $\mathrm{MS}^{43}$. In the HuPBMC EAE model, relatively few human B cells infiltrate the CNS relative to T cells: approximately $25-100 \mathrm{hCD} 19^{+} \mathrm{B}$ cells versus $10^{4}-10^{5} \mathrm{hCD}^{+} \mathrm{T}$ cells per spinal cord (Figures $4 \mathrm{~A}, \mathrm{~S} 5 \mathrm{~B}$ ). Despite relatively low overall counts, we observed a significant increase in the total number of $\mathrm{B}$ cells in the CNS of EBV $\mathrm{RRMS}^{+}$mice as compared to $\mathrm{EBV}^{-} \mathrm{HD}$ mice and a trending increase compared to $\mathrm{EBV}^{+} \mathrm{HD}$ mice, with an associated decrease in the periphery (Figure 4A), potentially indicating increased migration to the CNS in the RRMS recipient group. Total $\mathrm{B}$ cell infiltration did not differ, however, between $\mathrm{EBV}^{+}$and $\mathrm{EBV}^{-} \mathrm{HD}_{\text {groups. }}$ Though engrafted B cells reconstituted the spleen (approximately $10^{3}-10^{5} \mathrm{hCD} 19^{+} \mathrm{B}$ cells), EBV viral genomes were undetectable in the spleens of most mice at EAE endpoint, regardless of recipient group (Figure 4B), indicating peripheral viral reactivation from engrafted B cells is unlikely to have influenced disease outcomes. We further assessed whether an active EBV infection may play a role in promoting disease by measuring antibody production by EBV-specific B cells. Given that engrafted lymphocytes do 
not form organized germinal centers in NSG mouse lymphoid tissues, and are subsequently unable to promote class-switching and hypermutation of human B cells ${ }^{44,45}$, any EBV-specific IgG produced in these mice would indicate a reactivation of engrafted memory B cells rather than a novel response to infection post-engraftment. We confirmed the production of rhMOG-specific human IgM and the absence of rhMOG-specific human IgG in the serum of HuPBMC EAE mice (Figure S8A), indicating the engraftment of otherwise functionally responsive human B cells. In three separate $\mathrm{EBV}^{+}$recipient cohorts, no human IgG to EBV antigen VCA could be detected in serum after EAE induction (Figure 4C), which generated a strong response in corresponding donor serum (Figure 1B), suggesting that under these conditions, an active infection likely does not play a role in the enhancement of clinical disease.

Since the HuPBMC EAE mice did not experience systemic viral reactivation sufficient to explain the increased disease susceptibility and severity in $\mathrm{EBV}^{+}$recipient groups, we turned to evaluating indirect effects of latent infection on engrafted human $\mathrm{T}$ cells. We observed a significantly greater number of $\mathrm{hFOXP} 3^{+} \mathrm{CD}^{+}$regulatory $\mathrm{T}$ cells (Treg) in the $\mathrm{CNS}$ of $\mathrm{EBV}^{-} \mathrm{HD}$ recipient mice compared to the $\mathrm{EBV}^{+}$ groups (Figure 5A). The consequence of reduced Treg infiltration was highlighted by a stepwise increase in the ratio of human Th1 effector cells to Treg in both the CNS and periphery from $\mathrm{EBV}^{-} \mathrm{HD}$ to $\mathrm{EBV}^{+}$ $\mathrm{HD}$ and $\mathrm{EBV}^{+}$RRMS recipient groups (Figure 5B). Though not significantly different between HD groups, an increase in the human Tc1:Treg ratio was observed in the CNS of $\mathrm{EBV}^{+} \mathrm{RRMS}$ mice compared to HD groups (Figure 5C). The increased Tc1:Treg was also associated with greater Tc1 cytotoxicity, as assessed by granzyme B expression per cell (Figure 5D), and increased murine immune cell infiltration of the CNS (Figure 5E), indicating a more severe inflammatory response in $\mathrm{RRMS} \mathrm{EBV}^{+}$mice compared to HD groups. As sample collection was timed to maintain similar overall cumulative EAE scores between groups at endpoint, differences in CNS infiltration could not be correlated with greater clinical disease burden for RRMS and $\mathrm{EBV}^{+}$groups (Figure S8B). The data suggest that a history of EBV infection and RRMS diagnosis among donors leads to a compounded reduction in the accumulation of Tregs in the CNS with a concomitant increase in effector Th1 and Tc1 cells, and subsequent dysregulated inflammation leading to excessive CNS damage and worsened clinical outcomes in $\mathrm{EBV}^{+}$recipient groups. 


\section{DISCUSSION}

The findings of this study highlight the utility of PBMC-humanized EAE mice in modelling clinical and immunopathological aspects of MS. Immunocompromised NSG mice engrafted with female donor PBMCs were susceptible to the development of EAE symptoms and demyelination alike classical murine EAE models when induced with MOG antigens. As confirmed by histological analysis, engrafted human $\mathrm{CD}^{+} \mathrm{T}$ cells derived from an individual with RRMS were able to migrate to and infiltrate the mouse CNS and localized to areas of myelin damage, especially within the spinal cord and cerebellum. Moreover, the CNS of symptomatic mice was enriched for $\mathrm{hCD}^{+}$relative to $\mathrm{hCD}^{+} \mathrm{T}$ cells, which is commonly observed in post-mortem analysis of MS lesions ${ }^{46,47}$ but is not usually observed in typical murine EAE models ${ }^{48}$. We also observed equivalent infiltration of human $\mathrm{T}$ cells in the brain and the spinal cord, as opposed to the spinal cord dominant pathology of most murine EAE models ${ }^{48}$, indicating immunopathological similarity of HuPBMC EAE to MS in humans. We further determined that infiltrating human $\mathrm{T}$ cells produced predominantly Th1 and cytotoxic molecules that work alongside murine macrophages to demyelinate the CNS. Notably, demyelination of the mouse CNS occurs without substantial involvement of engrafted human macrophages, and human $\mathrm{CD}^{+} \mathrm{T}$ cells and murine immune cells can functionally interact to present myelin antigen ex vivo. Interspecies TCR:MHC interactions are potentially less efficient than autologous antigen presentation ${ }^{41}$, as evidenced by a relatively reduced rate of EAE symptom incidence compared to typical murine EAE models ${ }^{49}$. These interactions are, however, sufficient to produce demyelinating disease resulting in clinically measurable motor deficits. Though a previous study incorporated antigen-pulsed autologous dendritic cells (DC) ${ }^{50}$, our data suggest human DC priming is not necessary to produce clinical EAE symptoms in HuPBMC mice but may help promote human B cell class switching ${ }^{50}$. Immune system reconstitution of NSG mice with human PBMCs does not precisely replicate the composition of the donor PBMCs, nor all the nuanced contextual and site-specific complexities of the mammalian immune system ${ }^{40}$. The current data, however, collectively indicate that the HuPBMC EAE model is an interspecies system that exemplifies key elements of MS, and as such is a viable mouse model capable of providing novel clues for causes, biomarkers, and treatment of disease.

Humanized mice are more generally used to reduce cross-species differences in immunogenetics and reactivity, and to study pathogens that either do not infect animal models directly or lack suitable species homologs ${ }^{51-53}$. HuPBMC mice offer the possibility of pre-screening and selecting donors based on chosen genetic variants, environmental exposures, immunological conditions ${ }^{54,55}$, and, in the case of 
the HuPBMC EAE model, MS disease characteristics of interest, to create a personalized immune model. The increased brain infiltration in HuPBMC EAE mice may also aid in the study of MS pathology. Moreover, HuPBMC EAE mice could be used for the development and testing of disease modifying therapies specific to human immune targets, such as EBV-specific T cells ${ }^{56}$. Instances of promising results from biologic testing in preclinical EAE models that translated to worsened disease ${ }^{57,58}$ or serious side effects $^{59,60}$ in humans could ideally be identified in preclinical models with human immune systems before advancement to clinical trials. HuPBMC mice could also be used to circumvent the generation of costly transgenic mouse lines for immunogenetic studies. Furthermore, the HuPBMC EAE model reflects the epidemiological and clinical data associating EBV infection with increased risk of autoimmune disease.

PBMC donor history of EBV infection and a diagnosis of RRMS both exacerbated clinical disease susceptibility and severity in HuPBMC EAE mice. Consistent with the findings of Bjornevik et al. ${ }^{12}$, clinical EAE differences could not be attributed to CMV infection status, nor to reduced serum vitamin D levels. Interestingly, active infection by EBV was not required to exacerbate disease severity, as demonstrated by the absence of viral replication and memory B cell responses to EBV. Similarly, our group has previously demonstrated that viral reactivation does not occur following EAE induction in C57Bl/6 mice latently infected with the murine EBV homolog, gammaherpesvirus-68 ( $\gamma \mathrm{HV} 68$ ), and that $\gamma \mathrm{HV} 68$ does not actively infect the CNS during EAE ${ }^{61}$. B cell accumulation in the CNS of HuPBMC EAE mice was also not significantly different among mice derived from donors with or without EBV. Though relatively few B cells engraft and infiltrate the CNS compared to T cells, the possibility remains that engrafted EBV-specific or latently infected B cells may play a role through regulatory or non-antibody responses, such as cytokine production ${ }^{62}$ and antigen presentation ${ }^{63}$. Engrafted B cells of varying specificities and functionalities, which can act both protectively and pathogenically in $\mathrm{EAE}^{64,65}$, may also contribute to the enhancement of disease and the increased CNS inflammation observed in RRMS recipient mice compared to HD groups. Clinical post-mortem evidence has suggested that EBV could contribute to the development and/or progression of MS through infection of CNS-infiltrating B cells and tertiary lymphoid structures, leading to local inflammation ${ }^{66-68}$. With minimal B cell accumulation in the CNS at endpoint, the HuPBMC EAE model likely reflects earlier stages of MS, where B cell-containing lymphoid structures have not yet formed. An important limitation of PBMC humanized mice is the development of xenogeneic graft-versus-host disease, which limits the duration of experiments to $\sim 25$ days post-immunization in our experience. Further investigation in HuPBMC EAE mice will be required to assess the presence and influence of EBV-infected and EBV-specific B cells. Although there are 
multiple supported mechanisms by which EBV could promote an autoimmune environment, including infection and immortalization of autoreactive B cells ${ }^{69,70}$ and structural mimicry of CNS antigens ${ }^{13,71}$, our data suggests a role for $\mathrm{T}$ cell immunomodulation following latent infection.

HuPBMC EAE mice derived from $\mathrm{EBV}^{-} \mathrm{HD}$ had increased accumulation of Tregs in the CNS as compared to both $\mathrm{EBV}^{+}$groups, regardless of RRMS diagnosis, indicating an impairment of immune regulation resulting from EBV infection specifically. The abundance of effector Th1 cells relative to regulatory $\mathrm{T}$ cells consequently skews to promote a more inflammatory environment in mice derived from donors with a history of EBV infection that compounds when donors have also been diagnosed with RRMS. Though EBV infection alone was not necessary to enable EAE development, as demonstrated by reproducible $\mathrm{EBV}^{-} \mathrm{HD}$ mouse susceptibility to induction, the $\mathrm{EBV}^{+} \mathrm{HD}$ recipient group presented with an intermediate phenotype that resembled RRMS recipient mice in some ways more than the $\mathrm{EBV}^{-} \mathrm{HD}_{\text {group. }}$ As $\mathrm{T}$ cells are required for constant immune control of EBV-infected $\mathrm{B}$ cells ${ }^{72}$, latent infection could promote lasting change in predisposition to activation that may alter the balance of effector and regulatory responses toward a more 'MS-like' state. In the $\gamma$ HV68 EAE model, we also observe greater CD ${ }^{+}$T cell infiltration of the CNS, and particularly the brain, of latently infected mice, in addition to Th1-skewing, macrophage/microglia and DC activation, and reduced Treg proportions in the CNS and periphery ${ }^{61,73}$. Similar Th1-skewing and $\mathrm{CD}^{+} \mathrm{T}$ cell involvement was observed in latent $\gamma \mathrm{HV} 68$-infected mice induced with rheumatoid arthritis ${ }^{74}$, suggesting a common role for gammaherpesviruses in the exacerbation of and predisposition for autoimmunity. Ingelfinger et al. recently identified increased CD25 expression on transitional helper T cells as a defining phenotype of MS-derived PBMC in a monozygotic twin study, which the authors posit could be preferentially responsive to an environmental immune challenge such as EBV infection ${ }^{75}$. Zdimerova et al. also demonstrated a synergistic interaction between EBV infection and the MS risk allele HLA-DRB1*15:01 in stem cell-humanized mice, leading to increased T cell reactivity to myelin antigens ${ }^{76}$. A focus on the interplay of genetics and environmental exposures will enable more comprehensive investigation of MS risk factors and targeted therapies in the HuPBMC EAE model moving forward.

In summary, our current findings suggest that EBV-mediated risk for MS occurs prior to autoimmune insult and that either the establishment or maintenance of latent infection likely shapes subsequent $\mathrm{T}$ cell reactivity prior to or during initiation of MS. The data supports prevention of EBV infection and establishment of latency as a strong avenue for MS preventative strategies. 


\section{FIGURES}

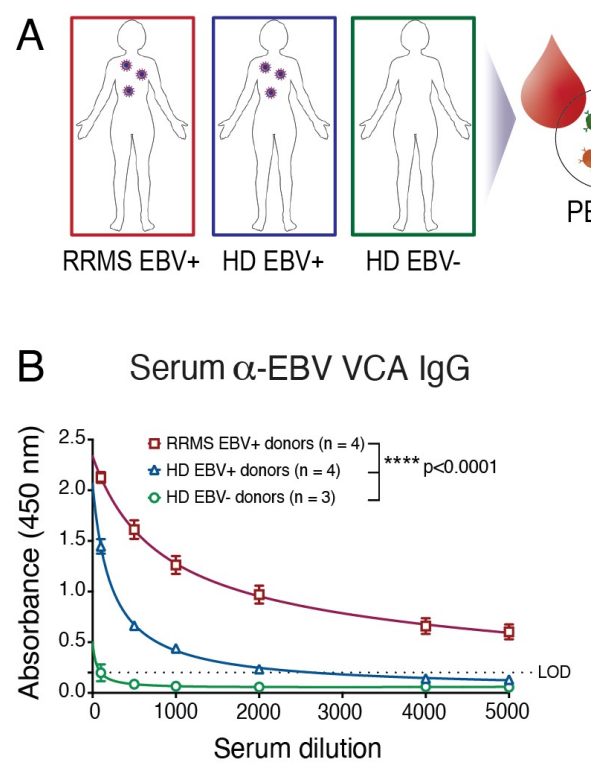

E Clinical disease score

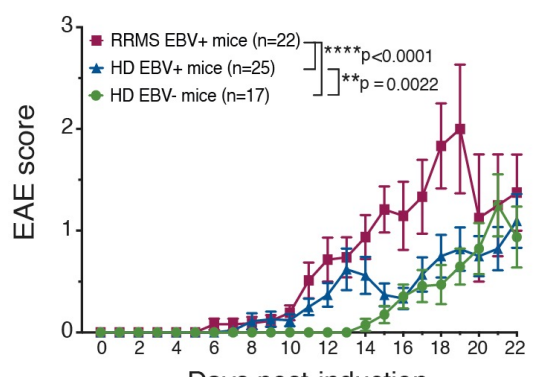

Days post-induction
C Serum $\alpha$-EBV EBNA-1 IgG

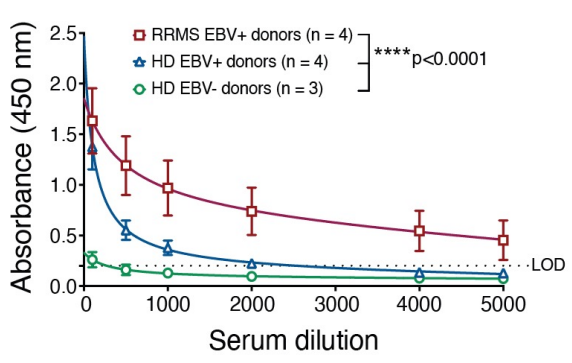

$\mathrm{F}$

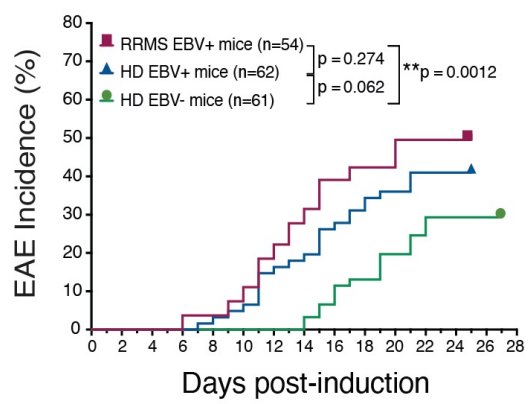

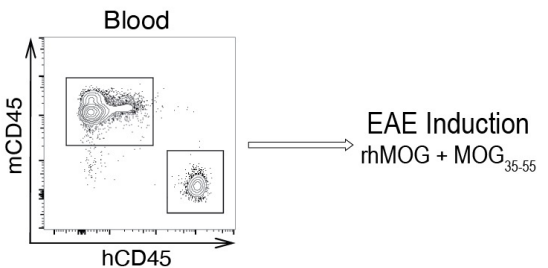

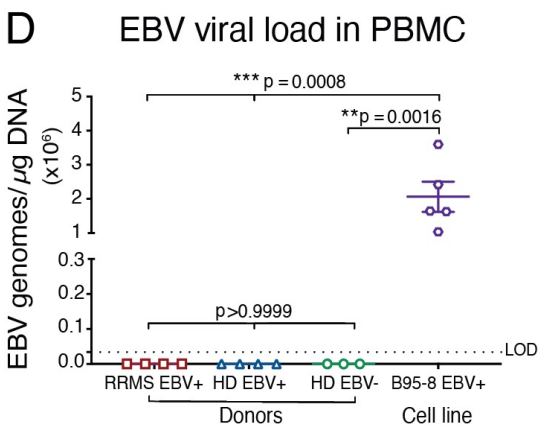

G Symptom onset

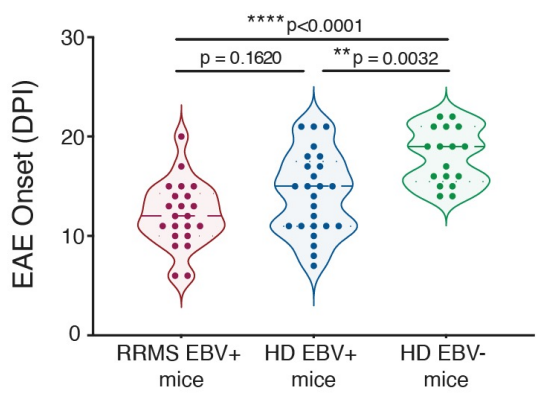

Figure 1. Donor EBV infection and RRMS diagnosis worsen clinical outcomes in HuPBMC EAE mice. (A) Experimental design: Donor PBMCs isolated from women with or without a history of EBV infection and an RRMS diagnosis were used to engraft immunocompromised NSG mice. Following a three-week reconstitution period and confirmation of circulating human $\mathrm{CD}^{+} 5^{+}$cell repopulation, humanized NSG mice (HuPBMC) were immunized with MOG antigens to induce EAE. (B) Donor serum IgG specific to acute EBV antigen viral capsid antigen (VCA). (C) Donor serum IgG specific to latent EBV antigen Epstein-Barr nuclear antigen 1 (EBNA-1). For B and C, group data are shown as mean with SEM and were curve fit with a one-site total binding equation. Statistical differences in titre curves were assessed by ordinary two-way ANOVA. (D) Cell-associated EBV viral loads in donor PBMCs. Data are shown as mean with SEM and were analyzed by ordinary one-way ANOVA with Tukey's multiple 
comparisons test. For B - D, n = 3-4 donors/group and the lower limit of detection (LOD) for each assay is represented by a dashed line. (E) Clinical disease scores post-induction for symptomatic HuPBMC EAE mice. Data are shown as mean with SEM and curves were analyzed by ordinary two-way ANOVA $(\mathrm{n}=$ 17 - 25 mice/group derived from $3-4$ donors/group). (F) Incidence of clinical EAE symptoms postinduction. Data are shown as percentage of the group and curves were analyzed by Log-rank (MantelCox) test ( $\mathrm{n}=54-62 \mathrm{mice} /$ group derived from $3-4$ donors/group). (G) Day of EAE symptom onset post-induction (DPI). Distribution of individual data are shown with median and quartiles (dashed lines) and were analyzed by Brown-Forsythe and Welch ANOVA with Dunnett's T3 multiple comparisons test ( $\mathrm{n}=17-25 \mathrm{mice} /$ group derived from $3-4$ donors/group). $* * * * \mathrm{p}<0.0001, * * * \mathrm{p}<0.001, * * \mathrm{p}<0.01$. 

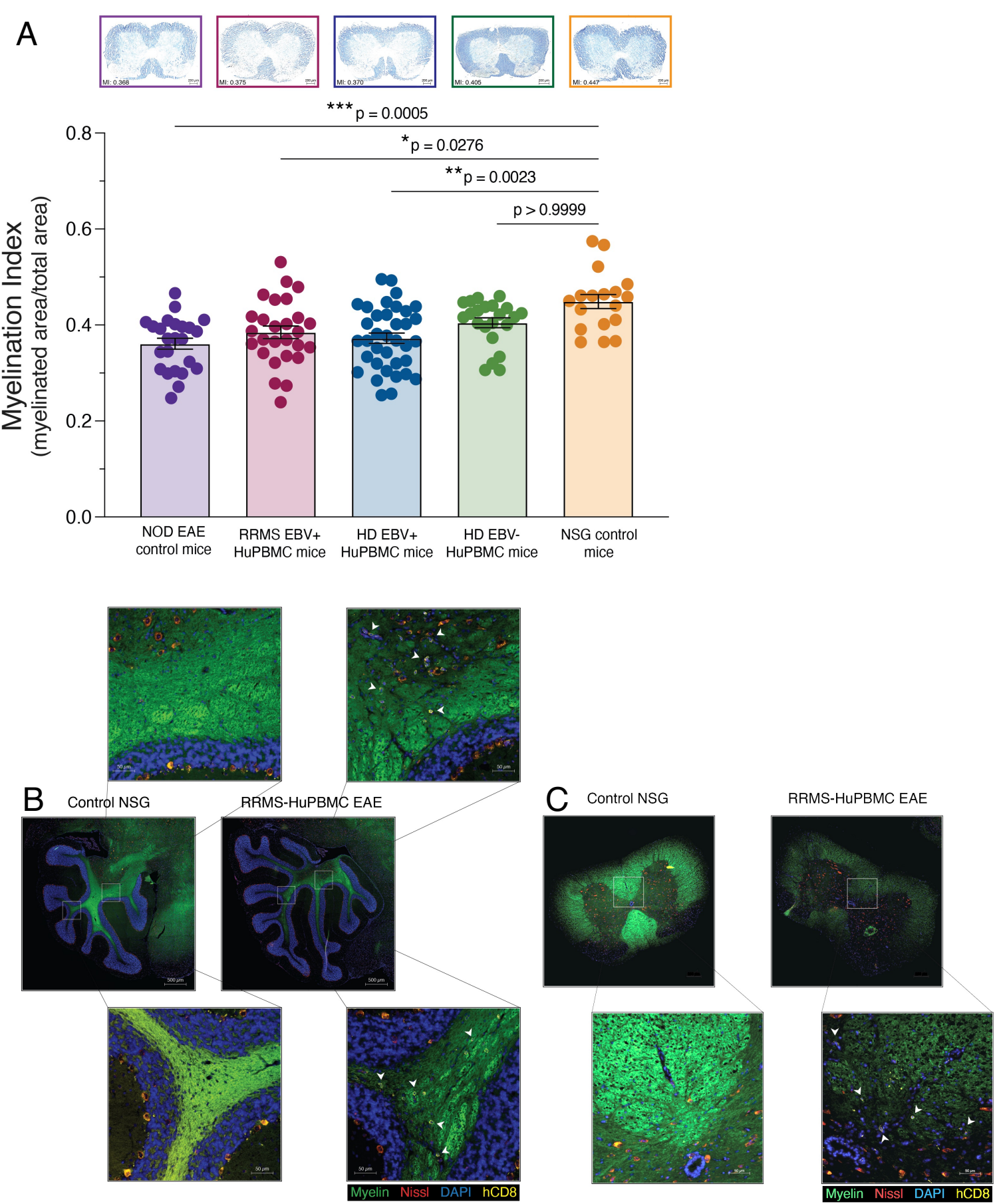

Figure 2. EAE induction in HuPBMC mice causes demyelination and human $T$ cell infiltration of the CNS. (A) Demyelination of the spinal cord in the HuPBMC EAE model. Perfused spinal cords were obtained days 19 - 25 post-induction ( $5-8$ days post-symptom onset) from HuPBMC EAE mice, and days 15 - 25 post-induction from NOD EAE mice. Eriochrome cyanine-stained sections (top) obtained from the lower thoracic region of the spinal cord show representative myelination indices (MI) for each 
of the respective group means. Individual data points represent averages of serial sections sampled from $4-6$ equidistant regions along the entire length of the spinal cord $(n=18$ regional points from 3 unengrafted NSG control mice; $\mathrm{n}=22-36$ regional points from $5-6$ mice/group for EAE-induced NOD and HuPBMC groups). Data are shown as mean with SEM and were analyzed by Kruskal-Wallis with Dunn's multiple comparisons test. ${ }^{* *} \mathrm{p}<0.001,{ }^{*} \mathrm{p}<0.01,{ }^{*} \mathrm{p}<0.05$. (B, C) Human CD8 ${ }^{+}$cells infiltrate the CNS of HuPBMC EAE mice engrafted with RRMS donor PBMCs. Representative images of cerebellar (B) and lumbar spinal cord (C) sections from an unengrafted control NSG mouse (left) and a symptomatic HuPBMC EAE mouse (right) derived from a donor with RRMS. Perfused tissues were collected day 15 post-EAE induction (day 4 post-symptom onset). Sections were labelled with FluoroMyelin (green), NeuroTrace 530/615 (red), DAPI (blue), and, for insets, anti-hCD8 (yellow). Example $\mathrm{hCD}^{+}$cells are indicated by white arrows. Scale bars indicate size as specified per panel, showing (A) $200 \mu \mathrm{m}$; (B) $500 \mu \mathrm{m}$, insets $50 \mu \mathrm{m}$; and (C) $200 \mu \mathrm{m}$, insets $50 \mu \mathrm{m}$. 


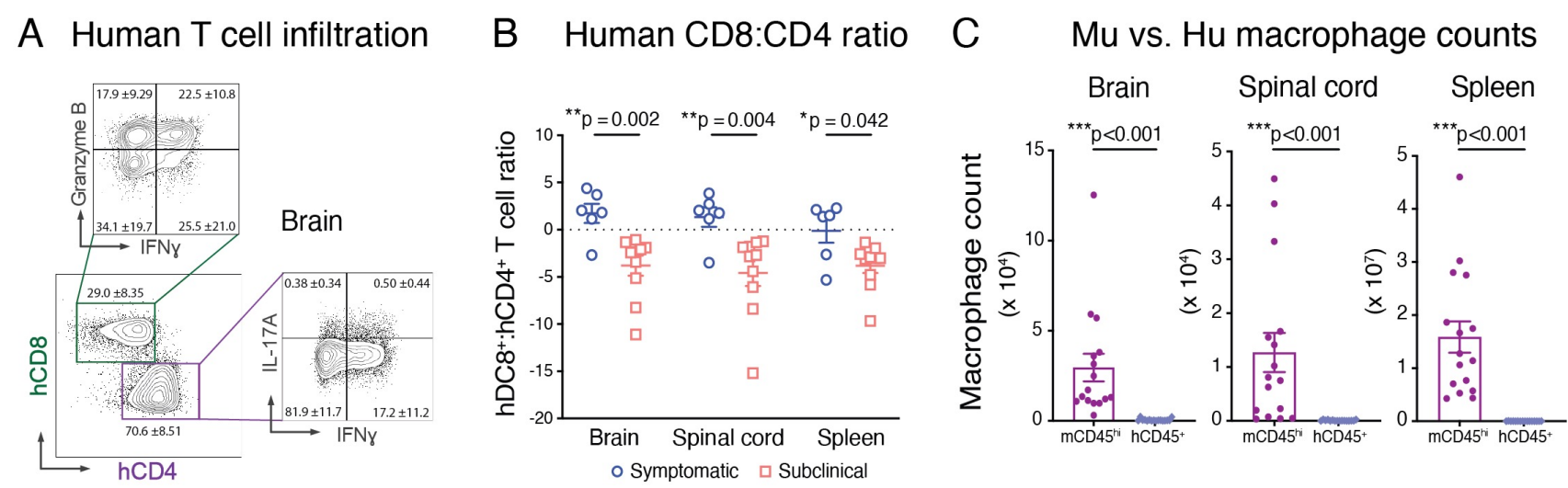

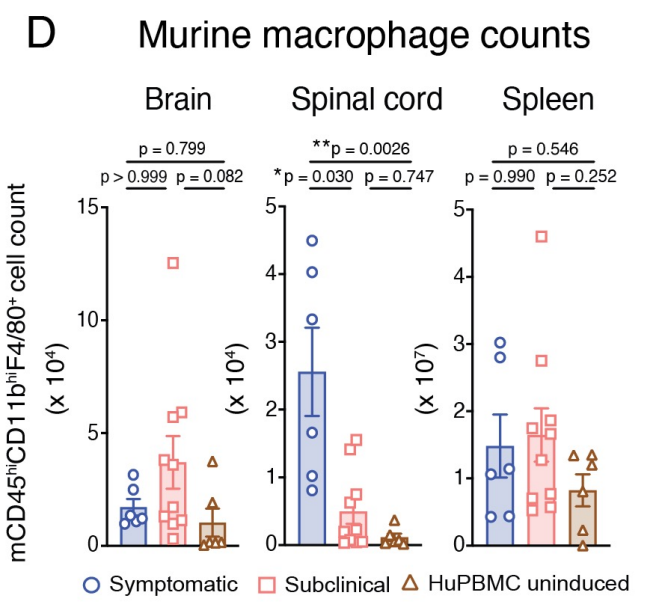

G Co-culture design

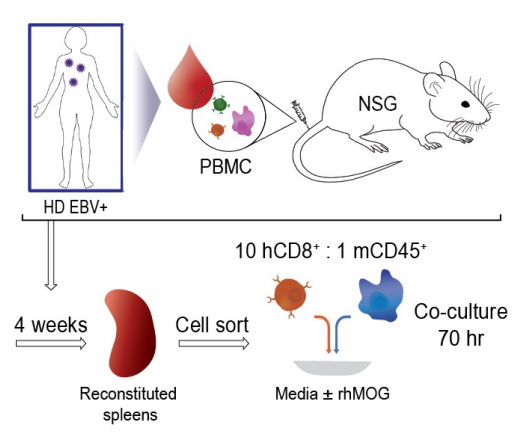

E Myelin phagocytosis

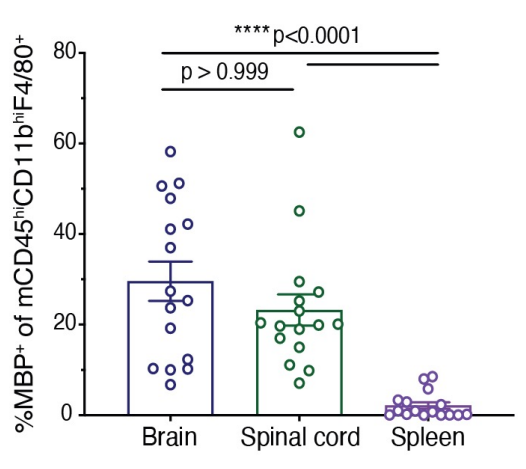

F hCD8 vs. MBP+Mu Mac

Spinal cord

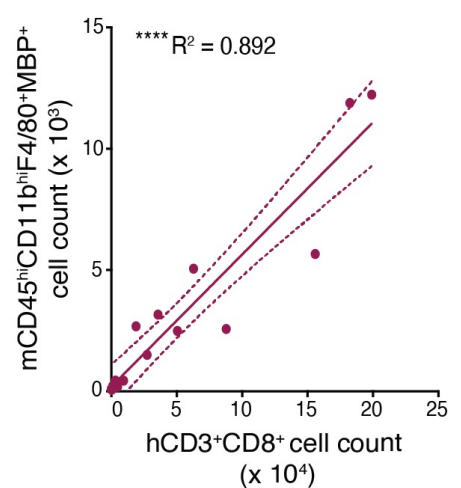

$\mathrm{H} \quad$ Interspecies antigen presentation

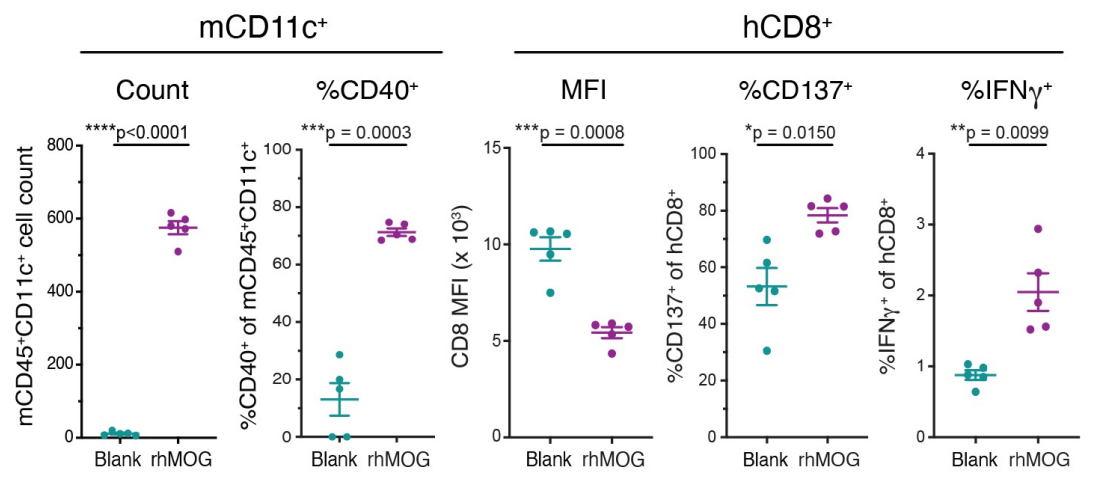

Figure 3. EAE in HuPBMC mice is mediated by human Th1 and Te1 cells and by murine macrophages. (A) Representative flow cytometric plots showing brain infiltrating $\mathrm{hCD} 3^{+} \mathrm{CD} 4^{+}$and $\mathrm{hCD} 3^{+} \mathrm{CD}^{+} \mathrm{T}$ cells and their respective cytokine expression. Perfused brains were collected day 22 postEAE induction. Data are shown as mean frequency of the parent population $\pm \mathrm{SD}(\mathrm{n}=18$ mice derived from one $\mathrm{EBV}^{+} \mathrm{HD}$ ). For $\mathrm{B}-\mathrm{F}$, perfused tissues were collected days 14 and 24 post-induction of cohorts 
derived from two unrelated $\mathrm{EBV}^{+} \mathrm{HD}$ PBMCs, and data were combined for analysis. (B) Human $\mathrm{CD}^{+}: \mathrm{CD}^{+} \mathrm{T}$ cell ratios in the CNS and spleens of HuPBMC EAE mice that either developed symptoms or remained subclinical. Data are shown as mean with SEM ( $\mathrm{n}=6-10 \mathrm{mice} /$ group). CNS data were analyzed by unpaired t-test with Welch's correction and spleen data by Mann-Whitney test. (C) Total numbers of murine $(\mathrm{Mu}) \mathrm{CD} 45^{\mathrm{hi}} \mathrm{CD} 11 \mathrm{~b}{ }^{\mathrm{hi}} \mathrm{F} 4 / 80^{+}$and human $(\mathrm{Hu}) \mathrm{CD} 45^{+} \mathrm{CD} 14^{+} \mathrm{CD} 68^{+}$macrophages in the CNS and spleens of HuPBMC EAE mice. Data are shown as mean with SEM ( $\mathrm{n}=16$ mice/group) and were analyzed by Mann-Whitney test. (D) Total numbers of murine CD $455^{\text {hi }} \mathrm{CD} 11 \mathrm{~b}{ }^{\text {hi }} \mathrm{F} 4 / 80^{+}$macrophages in the CNS and spleens of uninduced HuPBMC mice and EAE-induced HuPBMC mice that either developed symptoms or remained subclinical. Data are shown as mean with SEM ( $\mathrm{n}=6-10$ mice/group). CNS groups were analyzed by Kruskal-Wallis with Dunn's multiple comparisons test and spleen groups by Brown-Forsythe and Welch ANOVA with Dunnett's T3 multiple comparisons test. (E) Frequency of murine macrophages containing intracellular myelin basic protein (MBP) in HuPBMC EAE organs. Data are shown as mean with SEM ( $\mathrm{n}=16$ mice/group) and were analyzed by Kruskal-Wallis with Dunn's multiple comparisons test. (F) Correlation between the total numbers of $\mathrm{hCD} 3^{+} \mathrm{CD} 8^{+} \mathrm{T}$ cells and murine macrophages (Mac) containing intracellular MBP in the spinal cords of HuPBMC EAE mice. Data were analyzed by simple linear regression $\left(n=16\right.$ mice). Goodness of fit is indicated by $\mathrm{R}^{2}$ value, and the $95 \%$ confidence interval by dashed lines. $(\mathrm{G})$ Interspecies co-culture assay design: NSG mice $(n=4)$ were engrafted with $\mathrm{PBMC}$ from an $\mathrm{EBV}^{+} \mathrm{HD}$, and after four weeks, reconstituted spleens were processed and combined for fluorescence-activated cell sorting (FACS). Sorted cells were cultured $1 \mathrm{mCD} 45^{+}: 10 \mathrm{hCD} 8^{+}$ cells per well in blank or rhMOG-supplemented complete culture medium for 70 hours. $(\mathrm{H})$ Changes in $\mathrm{mCD} 11 \mathrm{c}^{+}$and $\mathrm{hCD}^{+}$cell marker expression following myelin antigen exposure in culture. Data are shown as mean with SEM ( $=5$ replicate wells/group) and analyzed by unpaired t-test with Welch's correction. Median fluorescence intensity (MFI). ${ }^{* * * *} \mathrm{p}<0.0001,{ }^{* * *} \mathrm{p}<0.001,{ }^{* *} \mathrm{p}<0.01,{ }^{*} \mathrm{p}<0.05$. 

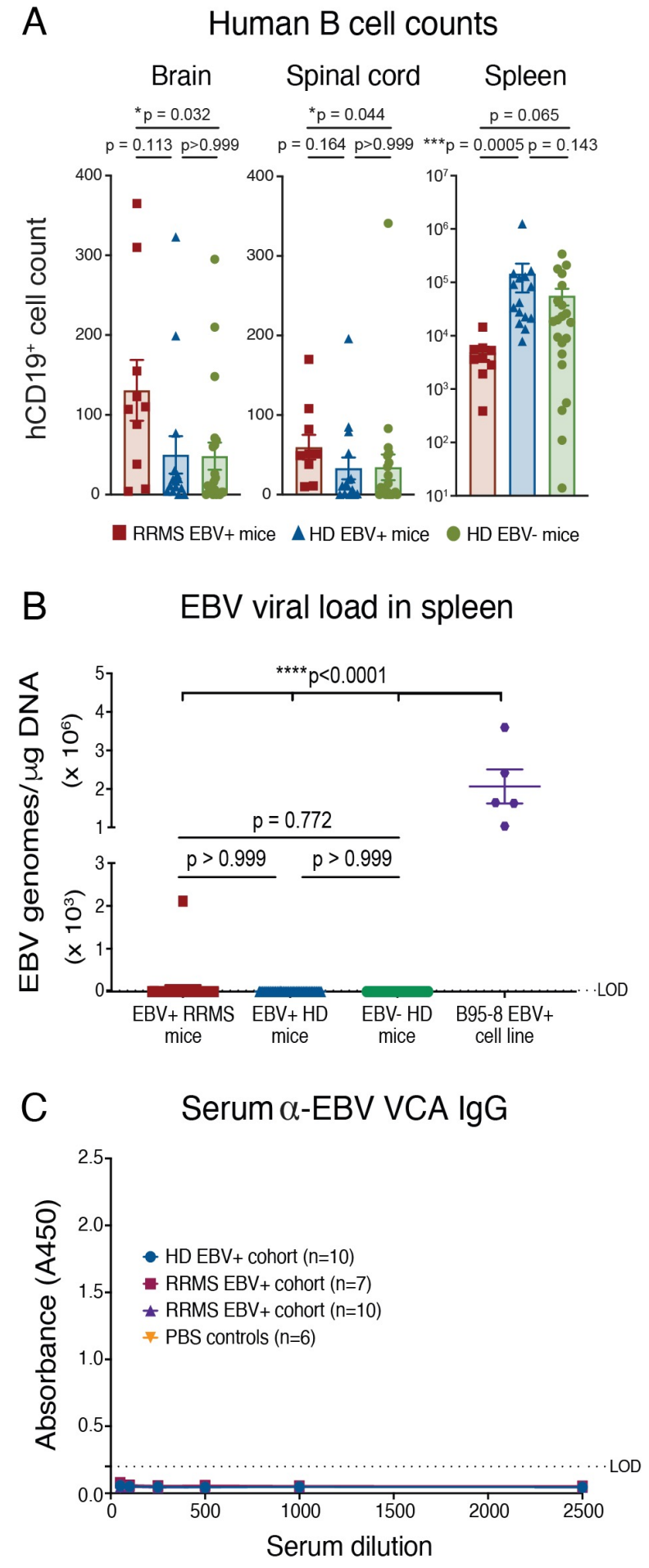

Figure 4. The influence of donor EBV and RRMS status on clinical outcomes in HuPBMC EAE mice is not driven by viral reactivation. (A) Total hCD $19^{+} \mathrm{B}$ cell counts in HuPBMC EAE organs by donor EBV and RRMS status. Perfused organs were collected days 15 - 27 post-EAE induction (average 5 - 10 days post-symptom onset). Data are shown as mean with SEM $(\mathrm{n}=10-21 \mathrm{mice} /$ group derived from one donor/group) and were analyzed by Kruskal-Wallis with Dunn's multiple comparisons test. (B) EBV genomes quantified in HuPBMC EAE splenocyte DNA. Group average symptom durations to endpoint were: $\mathrm{RRMS} \mathrm{EBV}^{+}$mice $6.0 \pm 1.6$ days, $\mathrm{HD} \mathrm{EBV}^{+}$mice $6.9 \pm 2.4$ days and $\mathrm{HD} \mathrm{EBV}^{-}$mice $7.5 \pm 1.4$ days. Data are shown as mean with SEM (n $=28-53$ mice/group derived from $2-4$ blood donors/group; $\mathrm{n}=5$ replicates for control $\mathrm{EBV}^{+} \mathrm{B} 95$ 8 cell line) and were analyzed by Kruskal-Wallis with Dunn's multiple comparisons test. Assay lower limit of detection (LOD) is represented by a dashed line. (C) Human IgG specific to EBV viral capsid antigen (VCA) in HuPBMC EAE mice derived from three unrelated $\mathrm{EBV}^{+}$donors. Serum samples were collected days $15-25$ post-induction (average $5-8$ days post-symptom onset) and data are shown as mean with SEM ( $\mathrm{n}=6-10$ mice/cohort derived from one donor/cohort). As all data points fell below the LOD, data were not assessed statistically. $* * * \mathrm{p}<0.0001, * * * \mathrm{p}<0.001, * \mathrm{p}<0.05$. 
A

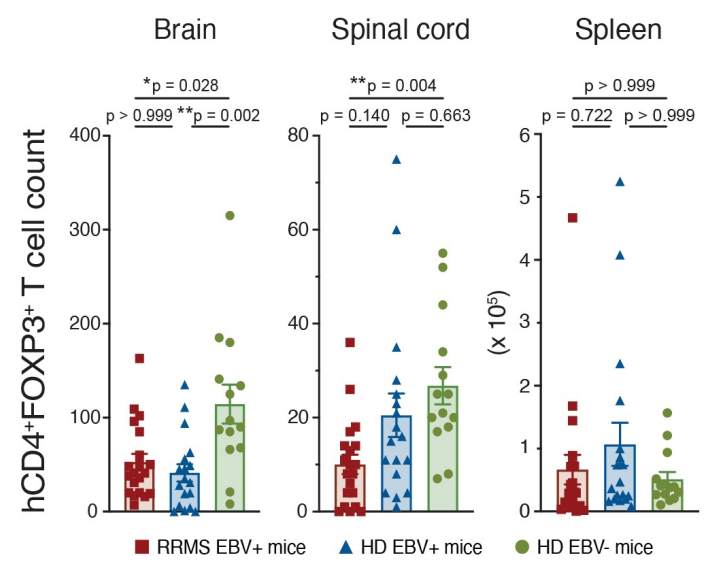

C

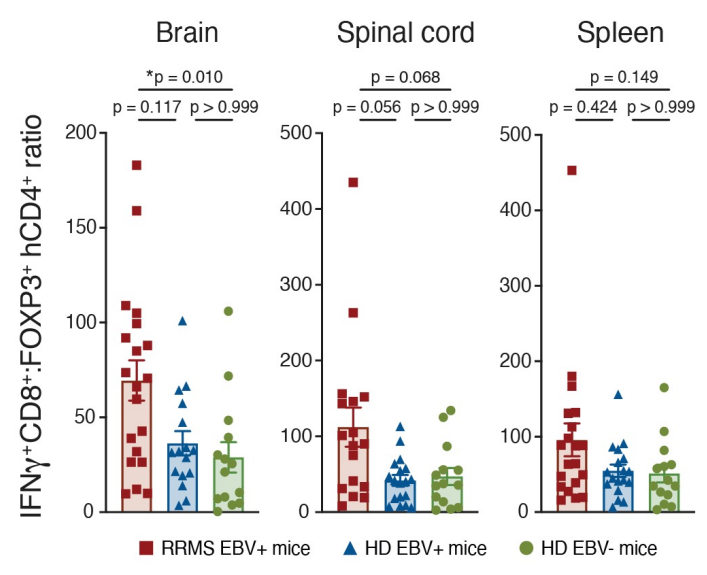

E Murine immune cell counts

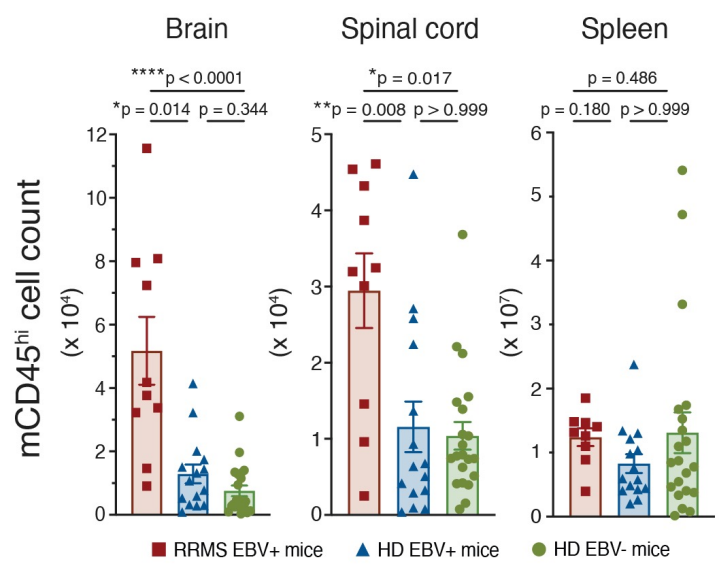

B Human Th1:Treg ratio

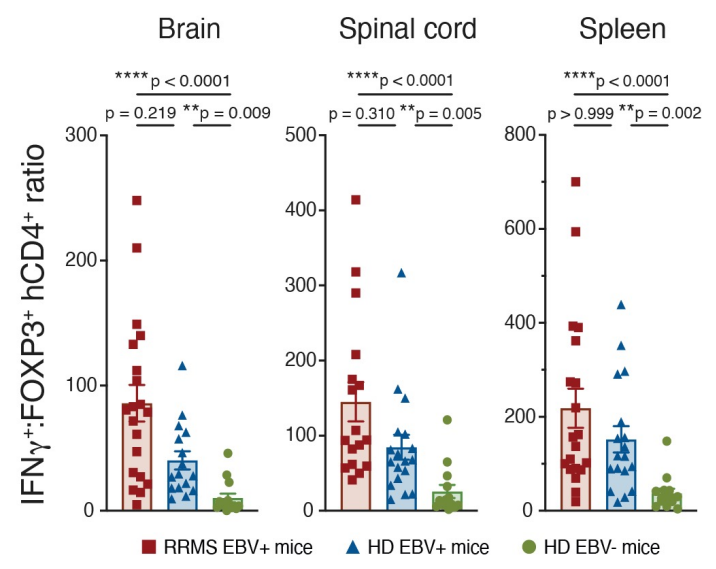

D Human CD8 T cell cytotoxicity

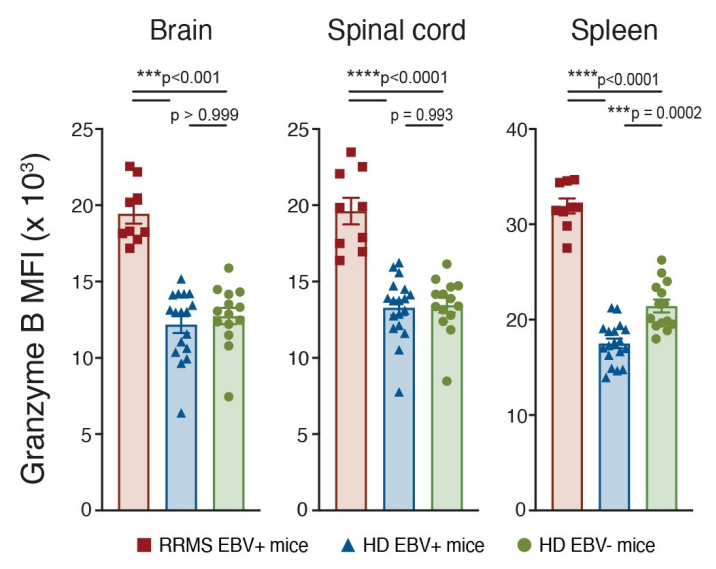

Figure 5. Cellular infiltration of the CNS in HuPBMC EAE is altered by donor EBV and RRMS status. (A) Total regulatory $\mathrm{T}$ cell $\left(\mathrm{hCD} 4^{+} \mathrm{FOXP}^{+}\right)$counts, (B) ratio of infiltrating $\mathrm{Th} 1\left(\mathrm{IFN} \gamma^{+} \mathrm{hCD}^{+}\right)$to regulatory hCD4 ${ }^{+} \mathrm{T}$ cells, (C) ratio of infiltrating $\mathrm{Tc} 1\left(\mathrm{IFN} \gamma^{+}\right) \mathrm{hCD}^{+}$to regulatory $\mathrm{hCD} 4^{+} \mathrm{T}$ cells, and 
(D) granzyme B expression by hCD8 ${ }^{+} \mathrm{T}$ cells in the CNS and spleens of HuPBMC EAE mice. For A - D, immune cells were isolated from perfused organs and stimulated with PMA and ionomycin (endpoint days $14-25$ post-induction, days 6 - 8 average post-symptom onset). Data are shown as mean with SEM and were analyzed by Brown-Forsythe and Welch ANOVA with Dunnett's T3 multiple comparisons test or by Kruskal-Wallis with Dunn's multiple comparisons test $(\mathrm{n}=14-20$ mice/group derived from $1-2$ donors/group). Median fluorescence intensity (MFI). (E) Murine CD45 immune cell counts in the CNS and spleens of HuPBMC EAE mice. Endpoints were days 15 - 27 post-induction (average 5 - 10 days post-symptom onset). Data are shown as mean with SEM ( $\mathrm{n}=10-21$ mice/group derived from one donor/group) and were analyzed by Kruskal-Wallis with Dunn's multiple comparisons test. $* * * * \mathrm{p}<0.0001, * * * \mathrm{p}<0.001, * * \mathrm{p}<0.01,{ }^{*} \mathrm{p}<0.05$. 
Table 1. PBMC donor demographics, disease characteristics, and serology. All RRMS and healthy donors were female. RRMS participants were treatment naïve and in clinical remission at the time of donation. Abbreviations: Healthy donor, HD; Expanded Disability Status Scale, EDSS; Viral capsid antigen, VCA; Epstein-Barr nuclear antigen 1, EBNA-1; Cytomegalovirus, CMV.

\begin{tabular}{|c|c|c|c|c|c|c|c|c|}
\hline Donor ID & $\begin{array}{c}\text { Age } \\
\text { (years) }\end{array}$ & $\begin{array}{l}\text { Age (years) at MS } \\
\text { symptom onset }\end{array}$ & $\begin{array}{l}\text { EDSS } \\
\text { score }\end{array}$ & $\begin{array}{l}\text { Disease } \\
\text { duration }\end{array}$ & $\begin{array}{l}\text { EBV IgG } \\
\text { serostatu }\end{array}$ & & $\begin{array}{l}\text { CMV IgG } \\
\text { serostatus }\end{array}$ & $\begin{array}{l}\text { Serum 25-OH } \\
(\mathrm{ng} / \mathrm{mL})\end{array}$ \\
\hline MS-01 & 24 & 24 & 2.5 & 4 months & $\begin{array}{r}\text { VCA } \\
\text { EBNA-1 }\end{array}$ & $\begin{array}{l}+ \\
+\end{array}$ & + & 29.7 \\
\hline MS-02 & 31 & 31 & 2.5 & 6 months & $\begin{array}{r}\text { VCA } \\
\text { EBNA-1 }\end{array}$ & $\begin{array}{l}+ \\
-\end{array}$ & + & 34.9 \\
\hline MS-03 & 32 & 26 & 2.0 & 5 years & $\begin{array}{r}\text { VCA } \\
\text { EBNA-1 }\end{array}$ & $\begin{array}{l}+ \\
+\end{array}$ & - & 19.9 \\
\hline MS-04 & 39 & 31 & 2.0 & 7 years & $\begin{array}{r}V C A \\
\text { EBNA-1 }\end{array}$ & $\begin{array}{l}+ \\
+\end{array}$ & - & 66.5 \\
\hline HD-01 & 39 & $\mathrm{~N} / \mathrm{A}$ & $\mathrm{N} / \mathrm{A}$ & N/A & $\begin{array}{r}V C A \\
\text { EBNA-1 }\end{array}$ & $\begin{array}{l}+ \\
+\end{array}$ & - & 27.7 \\
\hline HD-02 & 25 & $\mathrm{~N} / \mathrm{A}$ & $\mathrm{N} / \mathrm{A}$ & N/A & $\begin{array}{r}V C A \\
\text { EBNA-1 }\end{array}$ & $\begin{array}{l}- \\
-\end{array}$ & - & 35.0 \\
\hline HD-03 & 26 & N/A & N/A & N/A & $\begin{array}{r}\text { VCA } \\
\text { EBNA-1 }\end{array}$ & - & - & 29.8 \\
\hline HD-04 & 23 & $\mathrm{~N} / \mathrm{A}$ & N/A & N/A & $\begin{array}{r}V C A \\
\text { EBNA-1 }\end{array}$ & $\begin{array}{l}+ \\
+\end{array}$ & + & 37.5 \\
\hline HD-05 & 19 & N/A & N/A & N/A & $\begin{array}{r}V C A \\
\text { EBNA-1 }\end{array}$ & - & + & 18.9 \\
\hline HD-06 & 25 & N/A & N/A & N/A & $\begin{array}{r}V C A \\
\text { EBNA-1 }\end{array}$ & $\begin{array}{l}+ \\
-\end{array}$ & + & 38.4 \\
\hline HD-07 & 28 & $\mathrm{~N} / \mathrm{A}$ & N/A & N/A & $\begin{array}{r}V C A \\
\text { EBNA-1 }\end{array}$ & $\begin{array}{l}+ \\
+\end{array}$ & - & 27.5 \\
\hline
\end{tabular}




\section{SUPPLEMENTARY FIGURES}
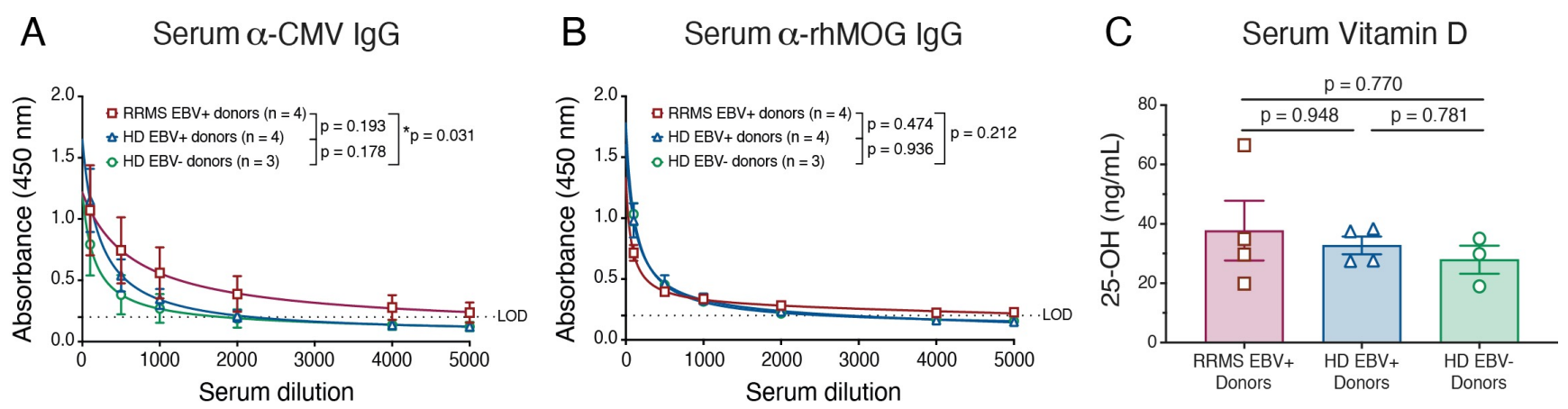

Figure S1. Donor serology for confounding MS risk factors. Donor serum IgG specific to (A) cytomegalovirus (CMV) antigens and (B) the inducing antigen, recombinant human myelin oligodendrocyte glycoprotein $\left(\mathrm{rhMOG}_{1-120}\right)$. For $\mathrm{A}$ and $\mathrm{B}$, group data are shown as mean with SEM $(\mathrm{n}=$ $3-4$ donors/group) and were curve fit with a one-site total binding equation. Statistical differences in titre curves were assessed by ordinary two-way ANOVA. The lower limit of detection (LOD) is represented by a dashed line. (C) Donor serum 25-OH vitamin D levels. Data are shown as mean with SEM (n = $3-$ 4 donors/group) and were analyzed by Brown-Forsythe and Welch ANOVA with Dunnett's T3 multiple comparisons test. ${ }^{*} \mathrm{p}<0.05$. 

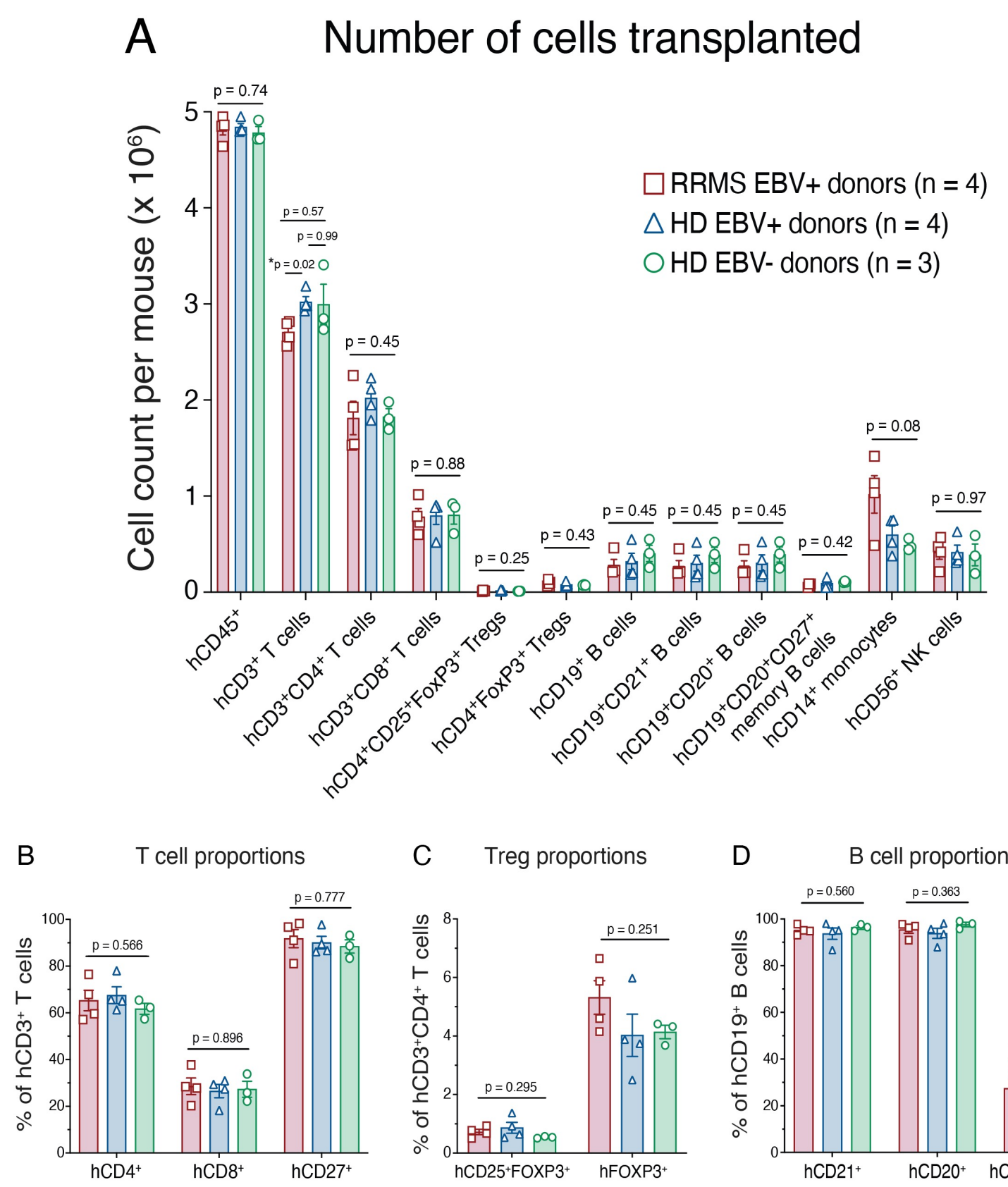

C Treg proportions
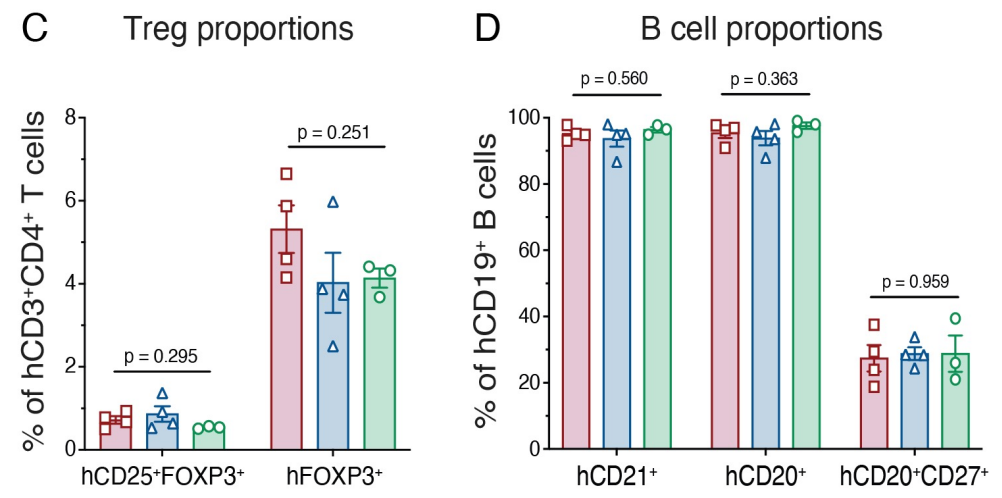

Figure S2. Phenotypic composition of donor PBMC injected into recipient NSG mice. (A) The number of cells from each major human immune subset transplanted per mouse and the relative proportions of (B) T cell, (C) regulatory T cell (Treg), and (D) B cell subsets among those transplanted cells. For A - D, data are shown as mean with SEM (n=3-4 donors/group) and were analyzed by BrownForsythe and Welch ANOVA with Dunnett's T3 multiple comparisons test or Kruskal-Wallis with Dunn's multiple comparisons test. Nonsignificant $\mathrm{p}$ values represent the overall test result for the three-group 
bioRxiv preprint doi: https://doi.org/10.1101/2022.02.23.481716; this version posted February 24, 2022. The copyright holder for this preprint (which was not certified by peer review) is the author/funder. All rights reserved. No reuse allowed without permission.

comparison, wherein each individual group comparison is also determined to be nonsignificant. The symbol legend in A is applicable to B - D. ${ }^{*} \mathrm{p}<0.05$. 
A
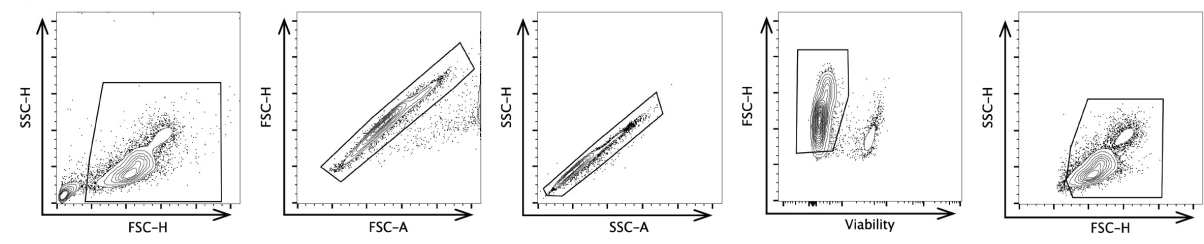

B
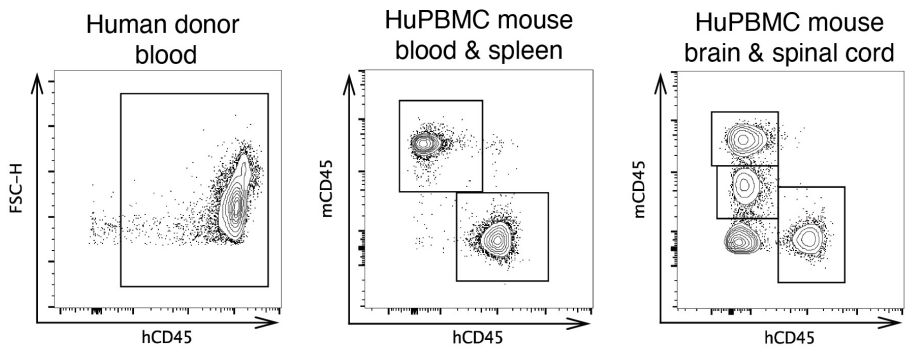

C
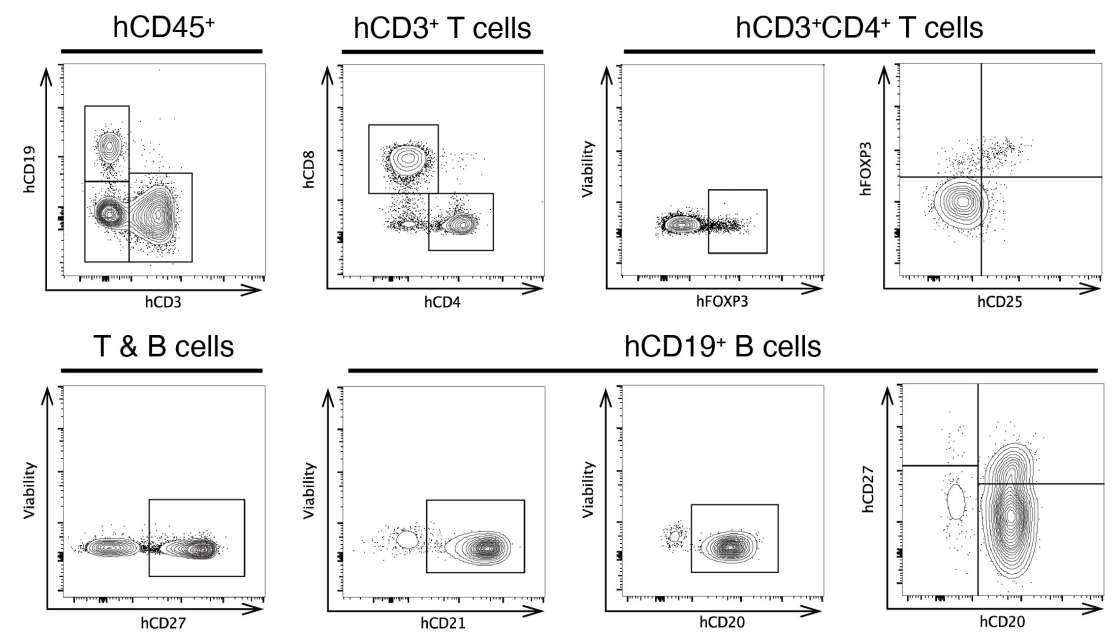

hCD19+ $\mathrm{B}$ cells
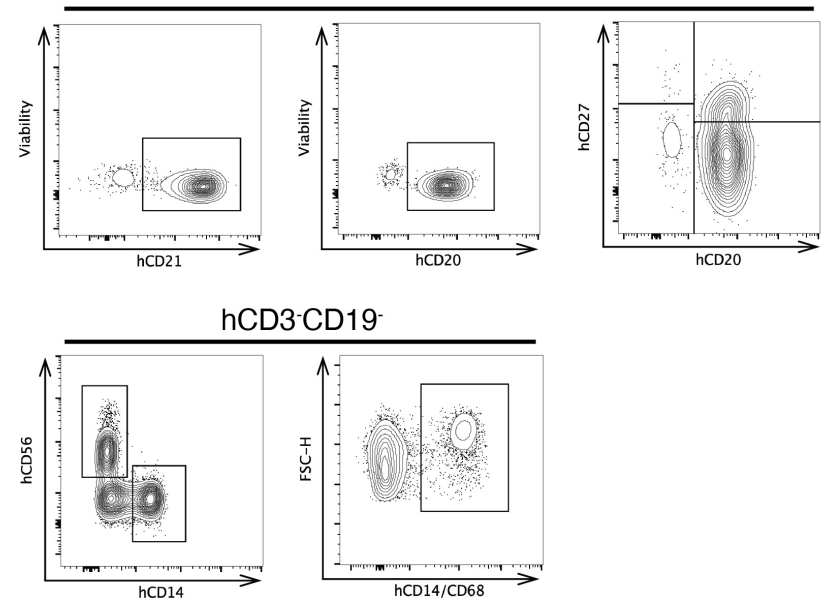

Figure S3. Gating strategies for flow cytometric data. (A) General cleanup steps applied to all samples. Gates were drawn successively from left to right: exclusion of cellular debris and doublets, by both size and complexity, followed by selection of viable cells and leukocytes. (B) Identification of human (h) and mouse $(\mathrm{m}) \mathrm{CD} 45^{+/ h i / l o}$ cell subsets based on source tissue. All further gates were successively drawn from within the appropriate species gate in $\mathrm{B}$, which are henceforth identified by an h- or $\mathrm{m}$ - prefix for each marker. For $\mathrm{C}-\mathrm{G}$, the parent gate for each representative plot is noted above. (C) Major human T cell, B cell, NK cell, and monocyte/macrophage subsets. 

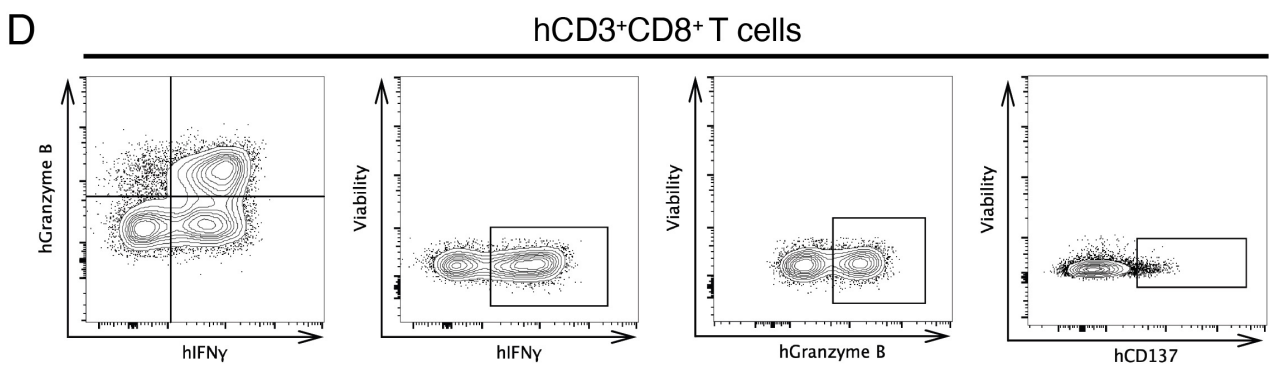

$\mathrm{E}$ hCD3 ${ }^{+} \mathrm{CD} 4{ }^{+} \mathrm{T}$ cells
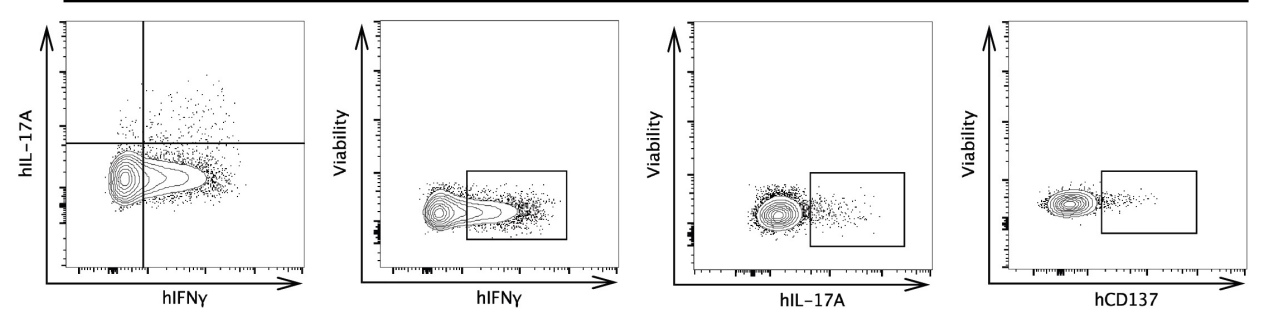

$\mathrm{F}$
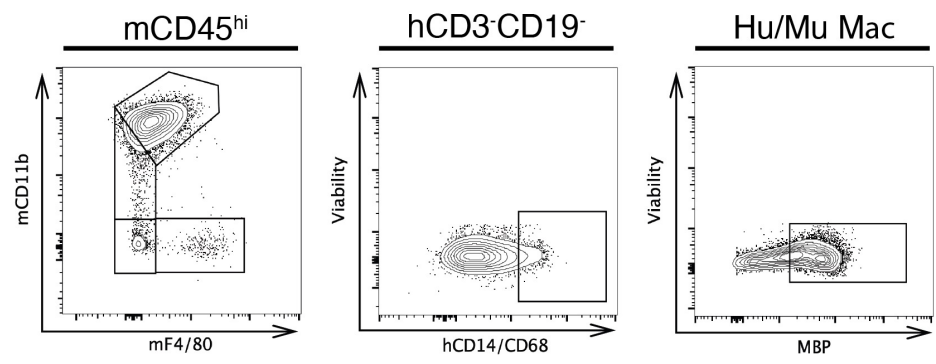

Figure S3. Gating strategies for flow cytometric data (continued). Cytokine and activation maker expression on (D) human $\mathrm{CD}^{+}$and (E) human $\mathrm{CD}^{+} \mathrm{T}$ cells. (F) Murine and human macrophage (Mac) subsets, and intracellular myelin basic protein (MBP) within phagocytes of either species. 

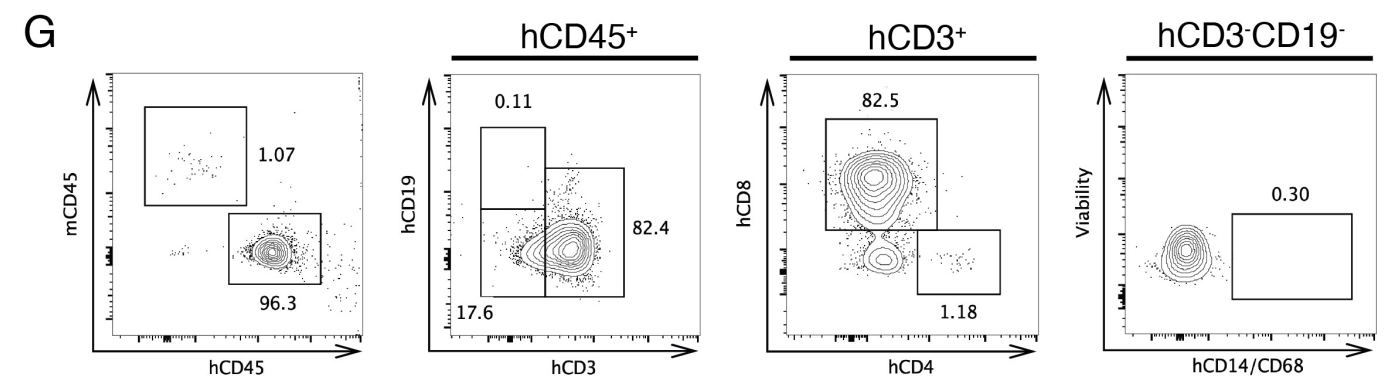

$\mathrm{H}$
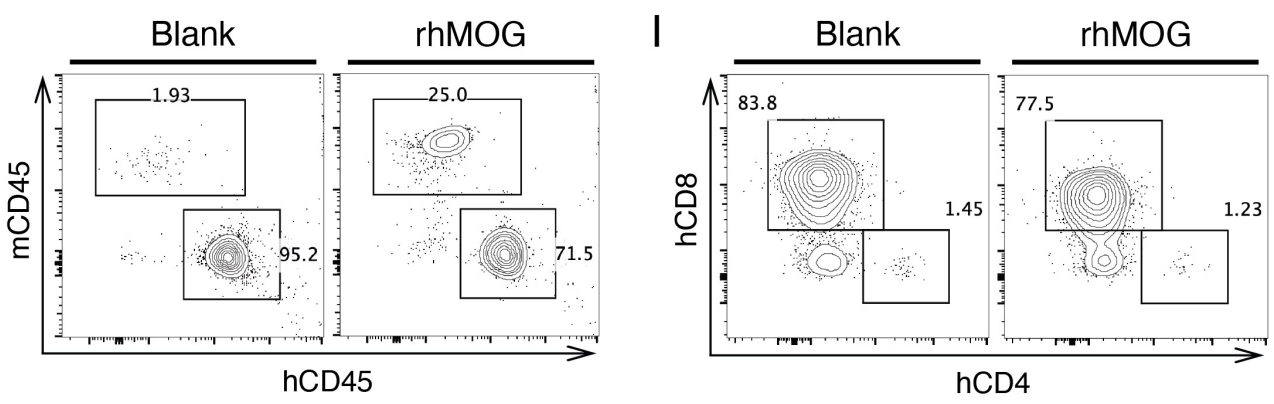

$J$
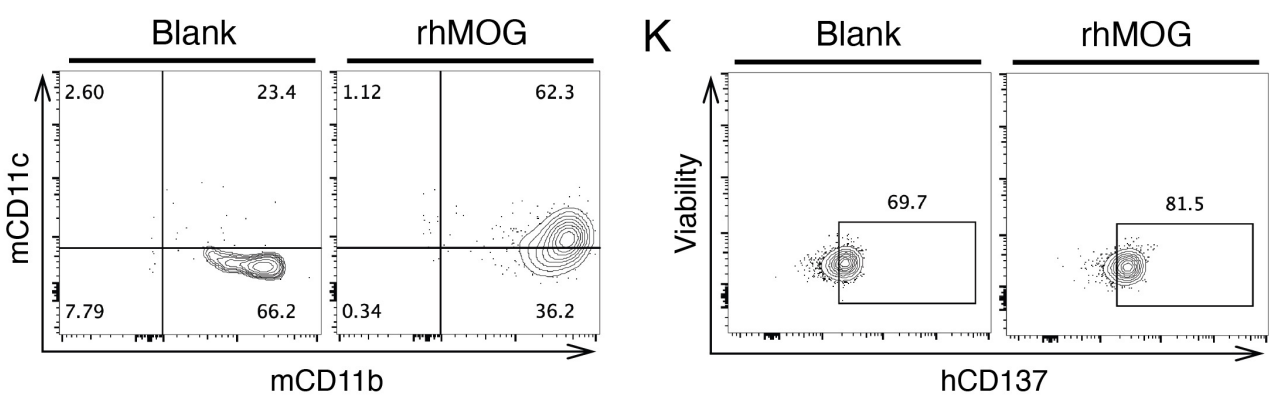

$\mathrm{L}$
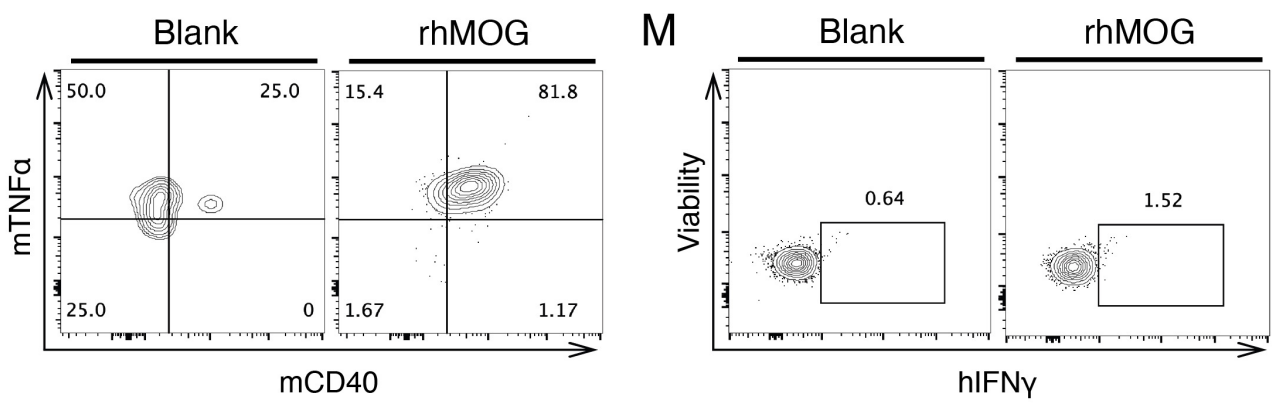

Figure S3. Gating strategies for flow cytometric data (continued). (G) Confirmation of FACS derived hCD $8^{+} \mathrm{T}$ cell purity. For $\mathrm{H}-\mathrm{M}$, representative flow plots were obtained from antigen presentation assays in which $\mathrm{hCD} 8^{+}$and $\mathrm{mCD} 45^{+}$cells were co-cultured in blank or rhMOG-supplemented media. Relative changes in $(\mathrm{H})$ human and murine immune cell proportions among total leukocytes, (I) co-receptor expression on $\mathrm{hCD}^{+} \mathrm{T}$ cells, $(\mathrm{J})$ innate murine immune cell proportions $\left(\mathrm{mCD} 45^{+}\right),(\mathrm{K})$ activation marker expression on $\mathrm{hCD} 3^{+} \mathrm{CD} 8^{+} \mathrm{T}$ cells, (L) activation marker expression on murine immune cells $\left(\mathrm{mCD} 45^{+}\right)$, and $(\mathrm{M})$ cytokine expression by $\mathrm{hCD} 3^{+} \mathrm{CD}^{+} \mathrm{T}$ cells. 

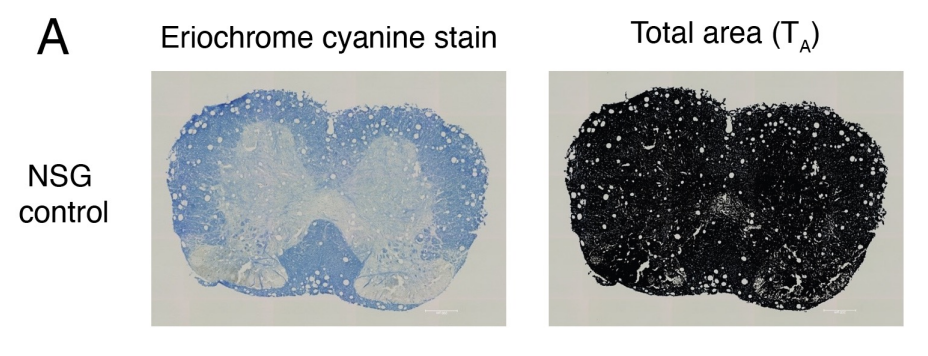

Myelinated area $\left(\mathrm{M}_{\mathrm{A}}\right)$
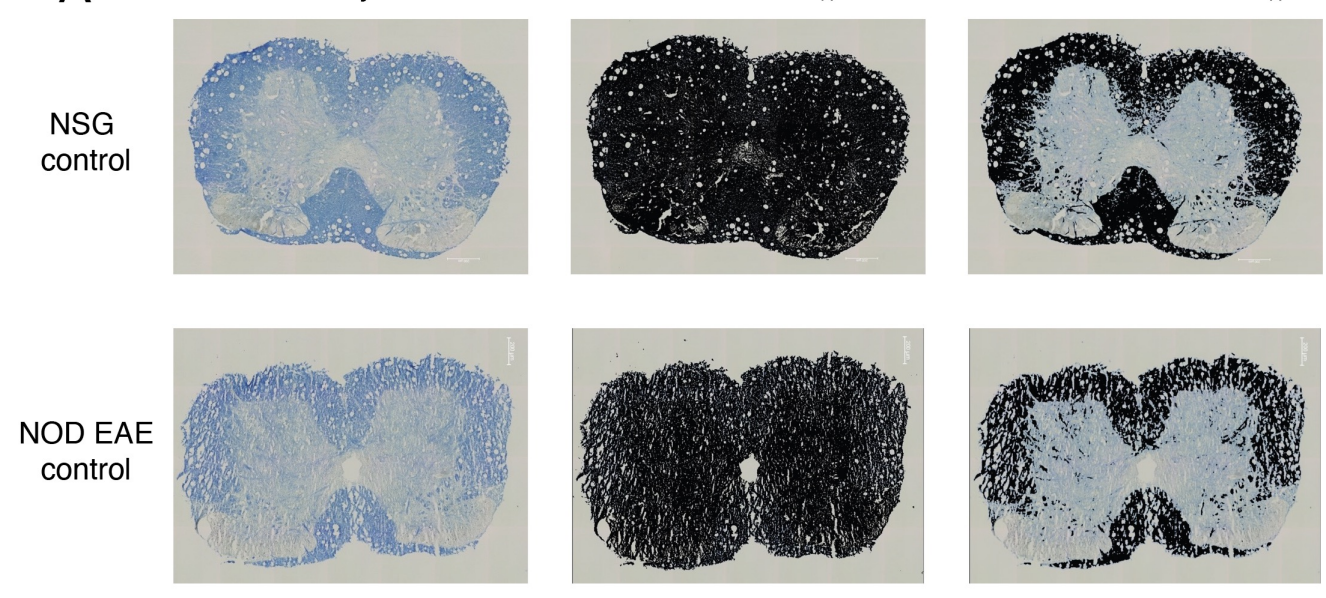

Myelination index $=M_{A} / T_{A}$
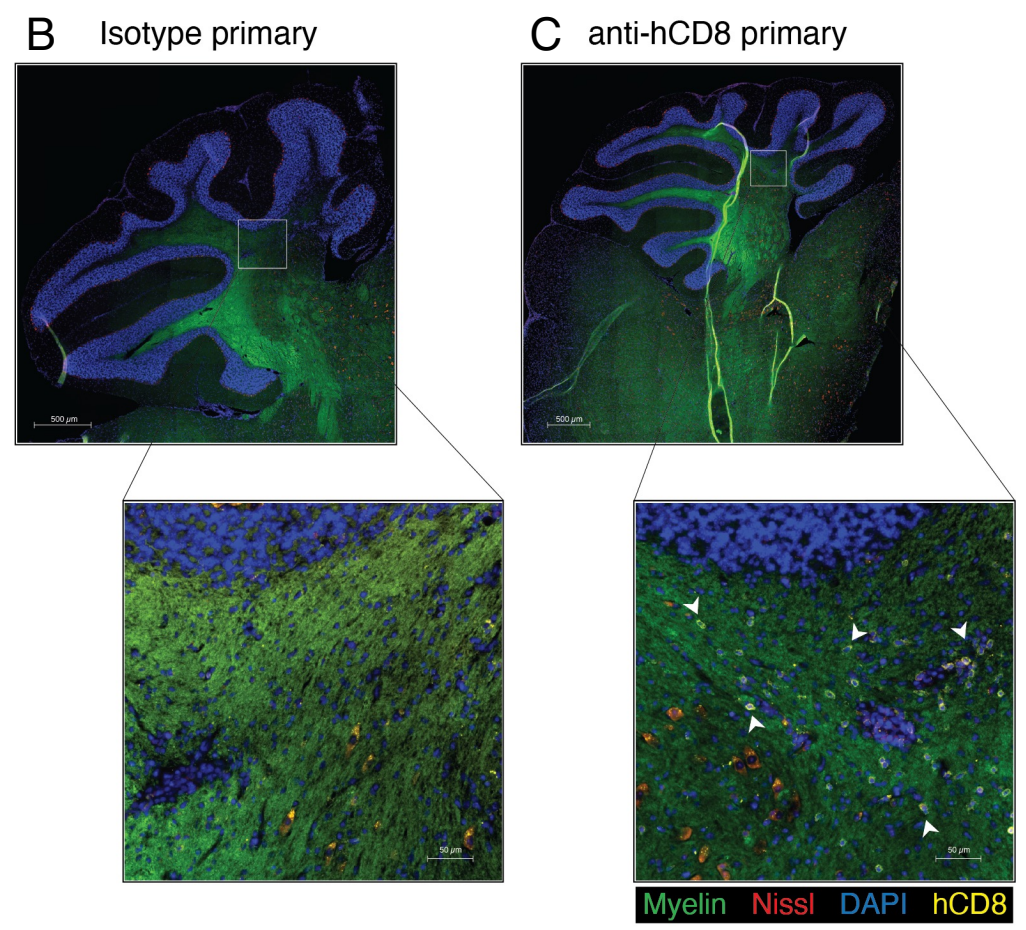

Figure S4. Histological analyses. Top panel: (A) Quantification of spinal cord myelination for NSG and NOD EAE control sections stained with eriochrome cyanine. Intensity thresholds were set consistently for total tissue area $\left(\mathrm{T}_{\mathrm{A}}\right)$ and myelinated area $\left(\mathrm{M}_{\mathrm{A}}\right)$, as measured based on individual scale bars, for all sections using Image J, and myelination index was calculated as a fraction of myelinated area of total tissue area. Bottom panel: Confirmation of human CD8 detection in the CNS by IHC. Representative images of serial cerebellar sections stained with either (B) isotype IgG primary antibody or (C) anti-human CD8 primary antibody (yellow). The perfused brain was collected day 15 post-EAE induction (day 4 post- 
symptom onset) from a symptomatic HuPBMC EAE mouse derived from a donor with RRMS. Sections were labelled with FluoroMyelin (green), NeuroTrace 530/615 (red), DAPI (blue), and the same secondary antibody. Example hCD8 ${ }^{+}$cells are indicted by white arrows. Scale bars indicate size as specified per panel, showing (A) $200 \mu \mathrm{m}$ and (B, C) $500 \mu \mathrm{m}$, insets $50 \mu \mathrm{m}$. 

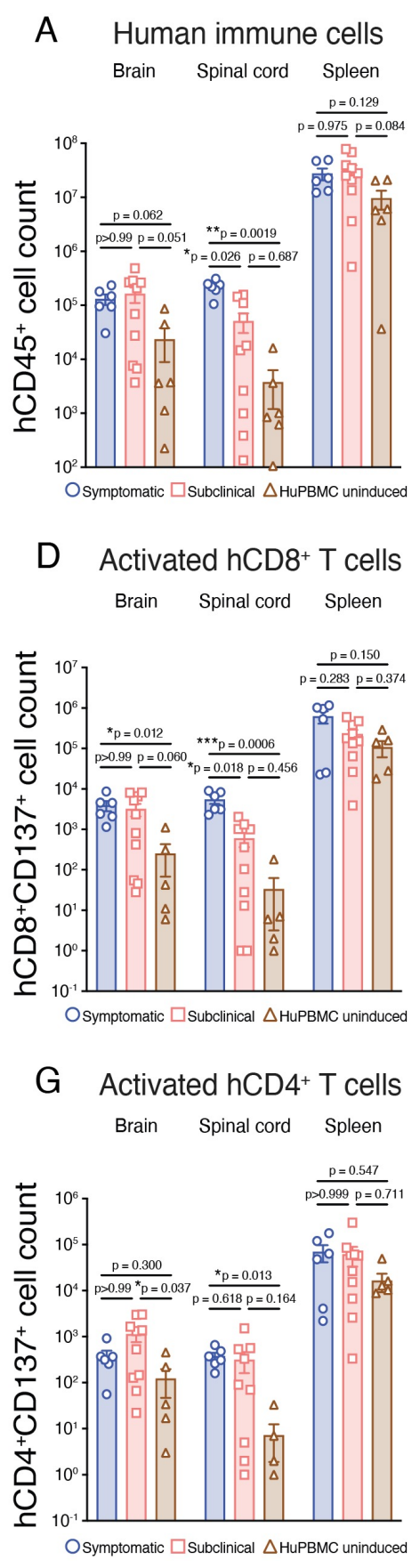
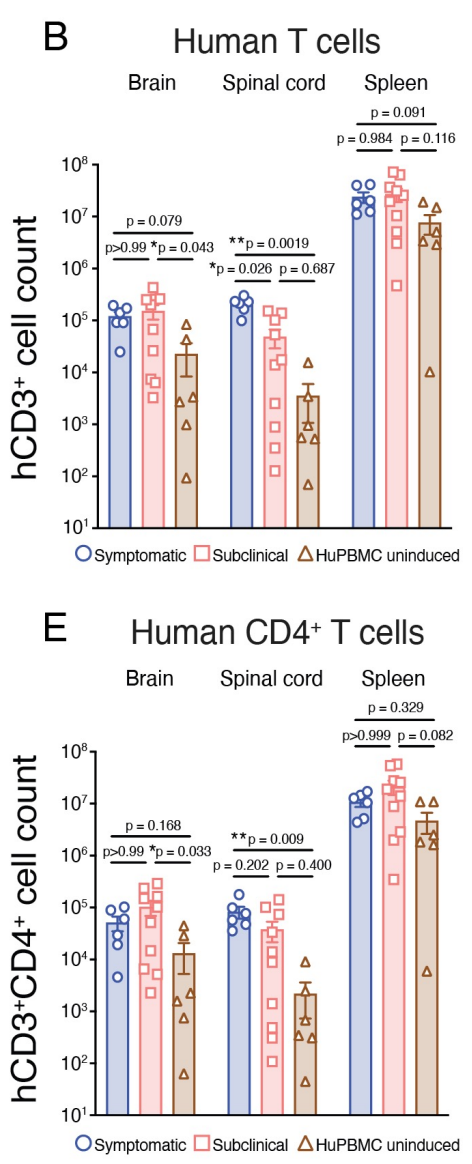

H Human macrophages

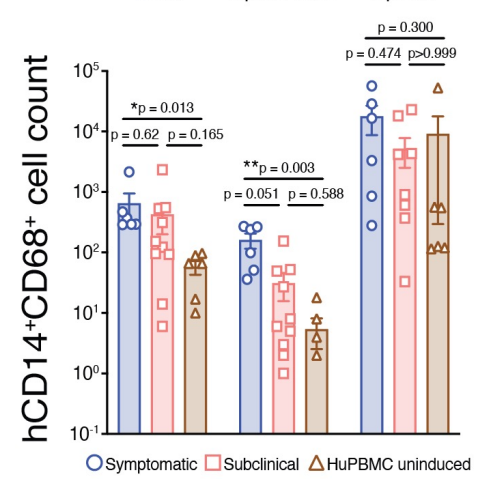

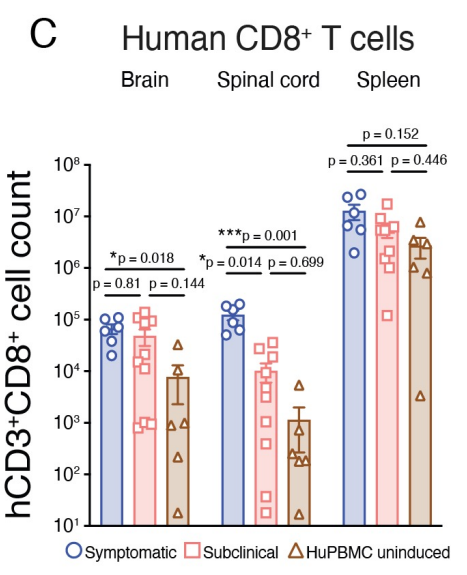

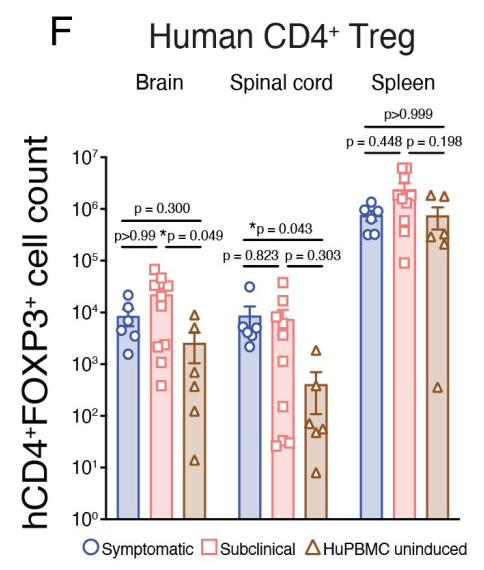

Figure S5. Degree of human immune cell infiltration of the CNS determines clinical EAE symptom incidence in HuPBMC mice. Total numbers of (A) hCD45 $5^{+}$immune cells, (B) hCD3 ${ }^{+} \mathrm{T}$ cells, (C) hCD $3^{+} \mathrm{CD} 8^{+} \mathrm{T}$ cells, (D) activated $\mathrm{hCD} 3^{+} \mathrm{CD} 8^{+} \mathrm{CD} 137^{+} \mathrm{T}$ cells, (E) $\mathrm{hCD} 3^{+} \mathrm{CD} 4^{+} \mathrm{T}$ cells, (F) hCD $3^{+} \mathrm{CD} 4{ }^{+} \mathrm{FOXP}^{+}$regulatory $\mathrm{T}$ cells, $(\mathrm{G})$ activated $\mathrm{hCD} 3{ }^{+} \mathrm{CD} 4{ }^{+} \mathrm{CD} 137^{+} \mathrm{T}$ cells and $(\mathrm{H}) \mathrm{hCD} 14^{+} \mathrm{CD} 68^{+}$ macrophages in the CNS and spleens of uninduced HuPBMC mice and EAE-induced HuPBMC mice that either developed symptoms or remained subclinical. Perfused tissues were collected days 14 and 24 post- 
induction of cohorts derived from two unrelated $\mathrm{EBV}^{+} \mathrm{HD} \mathrm{PBMC}$, and data were combined for analysis. Data are shown as mean with SEM ( $\mathrm{n}=6-10$ mice/group) and were analyzed by Brown-Forsythe and Welch ANOVA with Dunnett's T3 multiple comparisons test or Kruskal-Wallis with Dunn's multiple comparisons test. $* * * \mathrm{p}<0.001, * * \mathrm{p}<0.01, * \mathrm{p}<0.05$. 


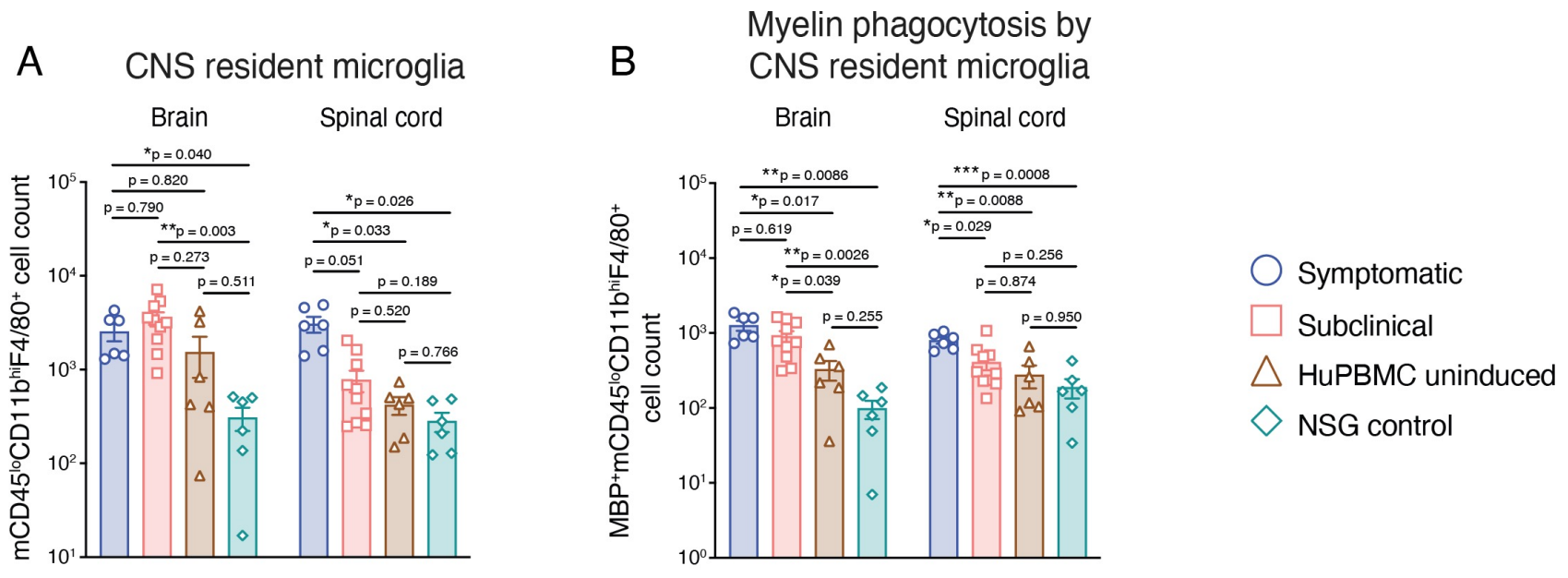

Figure S6. CNS resident microglia population expands and phagocytoses myelin in HuPBMC EAE. (A) $\mathrm{mCD} 45^{\text {lo }} \mathrm{CD} 11 \mathrm{~b}^{\mathrm{hi}} \mathrm{F} 4 / 80^{+}$cell counts and $(\mathrm{B})$ myelin basic protein $(\mathrm{MBP})^{+} \mathrm{mCD} 45^{\mathrm{lo}} \mathrm{CD} 11 \mathrm{~b}^{\mathrm{hi}} \mathrm{F} 4 / 80^{+}$ cell counts in the brains and spinal cords of NSG control mice, uninduced HuPBMC mice and EAEinduced HuPBMC mice that either developed symptoms or remained subclinical. Perfused tissues were collected days 14 and 24 post-induction of cohorts derived from two unrelated $\mathrm{EBV}^{+} \mathrm{HD} \mathrm{PBMC}$, and data were combined for analysis. Data are shown as mean with SEM ( $\mathrm{n}=6-10$ mice/group) and were analyzed by Brown-Forsythe and Welch ANOVA with Dunnett's T3 multiple comparisons. ${ }^{* *} \mathrm{p}<0.001,{ }^{* *} \mathrm{p}<0.01$, $* \mathrm{p}<0.05$. 


\section{A hCD8 $^{+}$vs. Mu Mac Spinal cord}
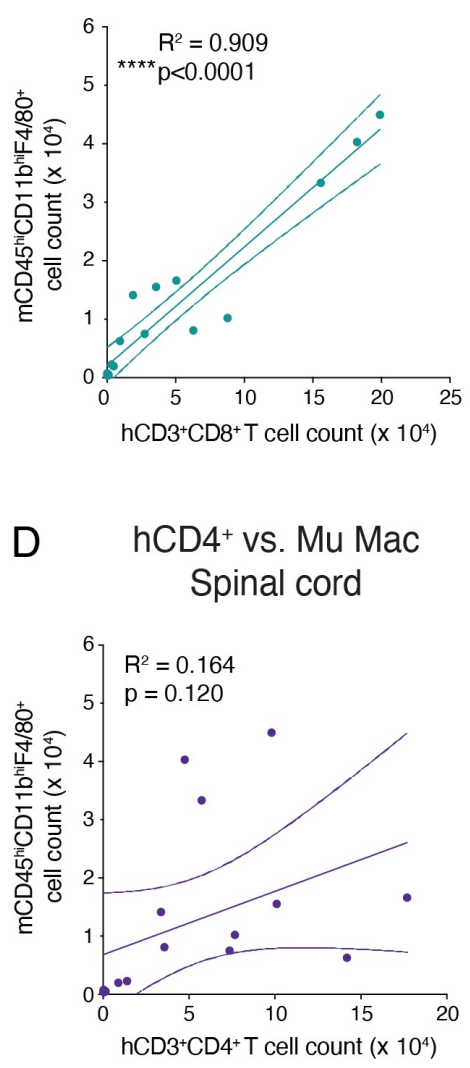
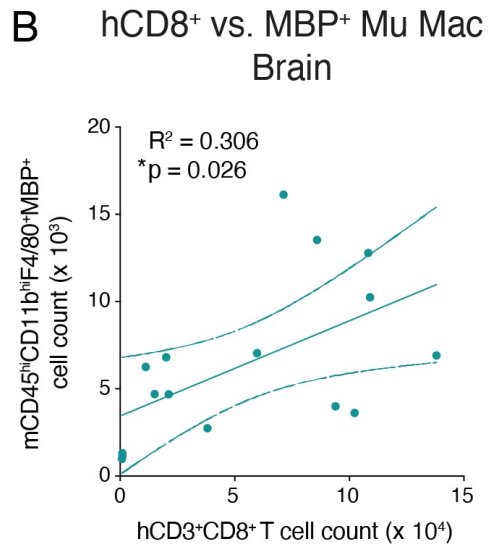

E $\quad$ hCD4 $^{+}$vs. MBP+ Mu Mac
Spinal cord

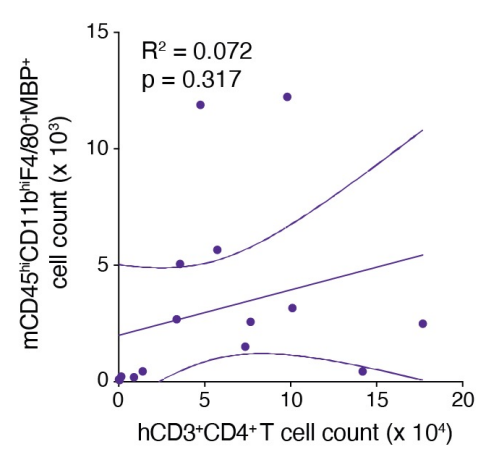

C hCD8 ${ }^{+}$vs. Hu Mac
Spinal cord

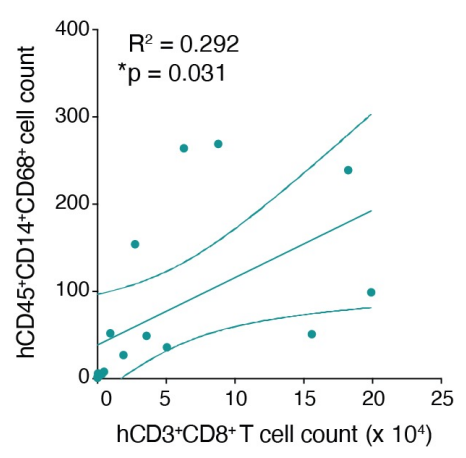

F $\quad$ hCD4+ vs. Hu Mac Spinal cord

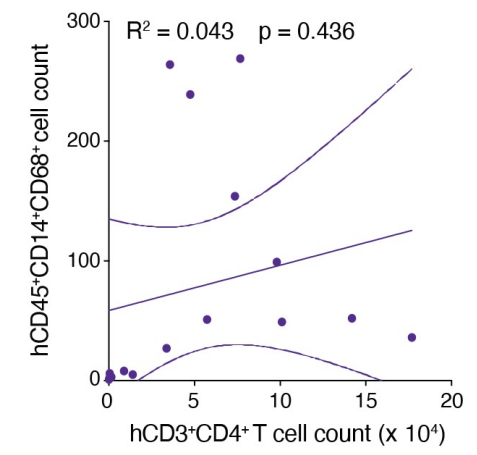

Figure S7. Relationship between infiltrating human $\mathbf{T}$ cells and murine or human macrophages in

HuPBMC EAE mice. Top row shows correlations between the total number of hCD $3^{+} \mathrm{CD} 8^{+} \mathrm{T}$ cells and (A) murine macrophages (Mac; $\mathrm{mCD} 45^{\mathrm{hi}} \mathrm{CD} 11 \mathrm{~b}{ }^{\mathrm{hi}} \mathrm{F} 4 / 80^{+}$) in the spinal cord, (B) murine macrophages in the brain containing intracellular myelin basic protein (MBP), and (C) human macrophages in the spinal cord. Bottom row shows correlations between the total number of $\mathrm{hCD} 3^{+} \mathrm{CD} 4^{+} \mathrm{T}$ cells and (A) murine macrophages, (B) murine macrophages containing intracellular MBP, and (C) human macrophages, all in the spinal cord. Perfused tissues were collected days 14 and 24 post-induction of cohorts derived from two unrelated $\mathrm{EBV}^{+} \mathrm{HD} \mathrm{PBMC}$, and data were combined for analysis. Data were analyzed by simple linear regression $\left(\mathrm{n}=16\right.$ mice). Goodness of fit is indicated by $\mathrm{R}^{2}$ value, and the $95 \%$ confidence interval by dashed lines. $* * * * \mathrm{p}<0.0001, * \mathrm{p}<0.05$. 

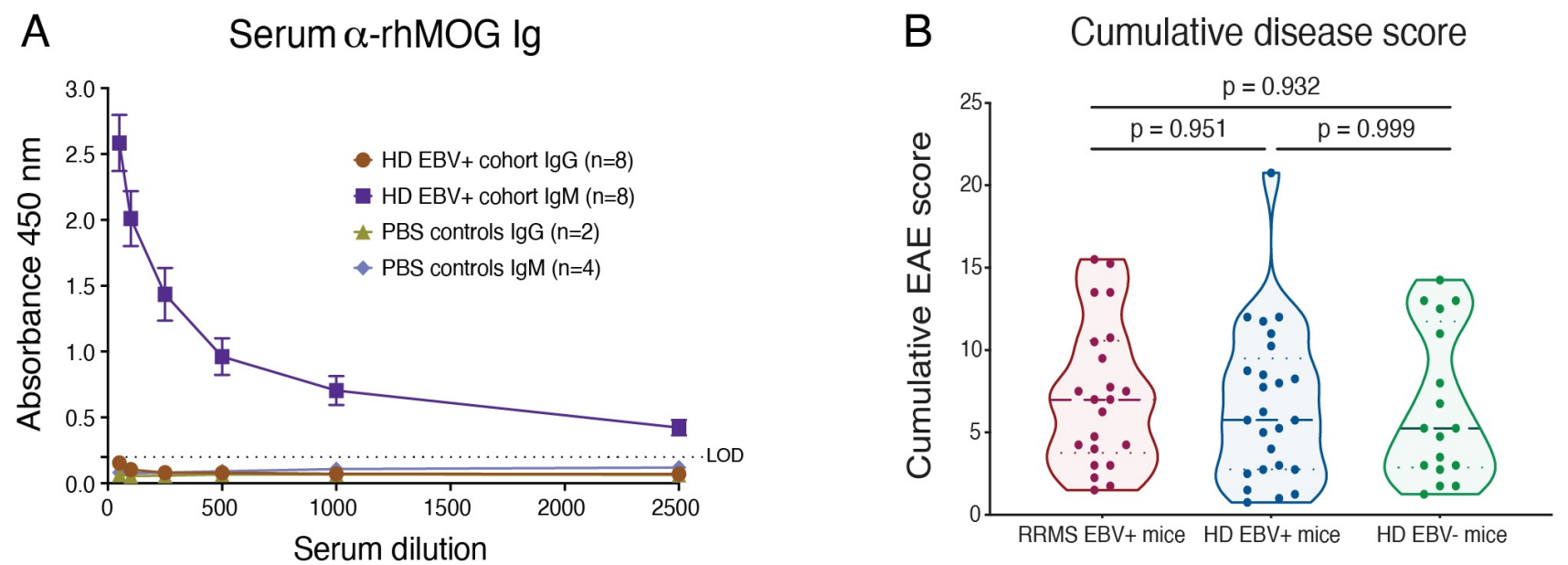

Figure S8. rhMOG antibody production and cumulative disease scores in HuPBMC EAE mice. (A) Deficiency in human Ig class-switching in response to rhMOG inducing antigen in HuPBMC EAE. Serum was collected from PBS-injected control NSG ( $\mathrm{n}=2-4$ mice/group) and from $\mathrm{HD} \mathrm{EBV}^{+}$mice (8 HuPBMC EAE mice/group derived from one donor/group) day 7 average symptom onset (days $15-22$ post-EAE induction). Data are shown as mean with SEM. As most group data points fell below the limit of detection (LOD), data were not assessed statistically. (B) Cumulative disease scores. Recipient group average symptom durations to endpoint were: RRMS EBV ${ }^{+}$mice $6.0 \pm 1.6$ days, $\mathrm{HD} \mathrm{EBV}^{+}$mice $6.9 \pm$ 2.4 days and $\mathrm{HD} \mathrm{EBV}^{-}$mice $7.5 \pm 1.4$ days. Distribution of individual data are shown with median and quartiles (dashed lines) and were analyzed by Brown-Forsythe and Welch ANOVA with Dunnett's T3 multiple comparisons test ( $\mathrm{n}=17-25$ mice/group derived from $3-4$ donors/group). 
Author contributions: JRA performed experiments, analyzed data, and prepared the manuscript. BKH performed immunofluorescent staining and imaging of CNS tissues. NMF performed in vitro co-culture assays and produced rhMOG protein. VF performed serum ELISAs. ARR performed myelin staining and quantification. IS coordinated phlebotomy, mouse breeding and aided with in vivo procedures. GV recruited and assessed donors with RRMS and provided input for the study design. LCO oversaw immunofluorescent imaging and provided input for the study design. JRA and MSH conceptualized the study, designed the methodology and interpreted results for discussion. MSH oversaw the study and manuscript preparation.

Funding sources: The study was funded by grants from the Multiple Sclerosis Society of Canada (MSSC), including the endMS personnel award program (JRA, NMF), the Canadian Institutes of Health Research (CIHR), the National Multiple Sclerosis Society (NMSS) and the University of British Columbia (UBC). The funders had no role in study design, data collection and interpretation, or the decision to submit the work for publication.

Declaration of interests: The authors have no conflicts of interest to disclose.

Acknowledgements: The authors thank the following individuals for their contributions to the study: Soren Gantt and Karen Simmons for providing the EBV BALF5 qPCR protocol; John Priatel for providing the B95-8 EBV ${ }^{+}$cell line; Jennifer Gommerman, Nancy Ruddle and Christopher Linington for providing the rhMOG-producing E. coli plasmid; Angela Lin and Michael Murphy for assistance with rhMOG protein production; Tanya Kadach for organizing blood donations at the Fraser Health MS Clinic; the staff at the Modified Barrier Facility for animal husbandry; Yu Gu for ELISA protocol development; Brankica Culibrk and Philma Molina for phlebotomy; Justin Wong and Andrew Johnson for assistance with FACS; Virginie Jean-Baptiste, Isobel Mouat and Erin Goldberg for assistance with animal monitoring. The authors express their gratitude to the blood donors for providing their time and samples to the study. 


\section{METHODS}

Further information and requests for resources and reagents should be directed to and will be fulfilled by the Lead Contact, Marc Horwitz (mhorwitz@mail.ubc.ca).

\section{Human participants}

Blood donation by human participants was approved by the University of British Columbia's Clinical Research Ethics Board and by the Fraser Health Authority, under protocol H16-02338. Individuals with RRMS were recruited at the Fraser Health MS Clinic (Burnaby, BC) under the supervision of Dr. Galina Vorobeychik. Unaffected, otherwise healthy donors were recruited at the Life Sciences Center (University of British Columbia). All donors were female, 19 - 39 years of age (mean age $31.5 \pm 6.1$ years for RRMS donors and $26.4 \pm 6.2$ years for HDs) and provided written informed consent prior to enrolment in the study, from November 2018 to August 2021. Donors with a definite RRMS diagnosis, according to Poser or 2010 McDonald criteria, and disease duration of less than 10 years, were confirmed as treatment naïve prior to donation (no previous use of any disease modifying therapies during lifetime). RRMS donors underwent a neurological exam the day of blood donation to assess Expanded Disability Status Scale (EDSS) score. Individuals with a progressive MS diagnosis or EDSS $>4$, that were male, pregnant, outside of the designated age range, or undergoing treatment were excluded from the present study.

\section{Donor sample processing}

Blood samples were obtained by venipuncture and assigned an alphanumeric code to protect donor identity. Whole blood (80 mL) was processed for PBMC isolation by Lymphoprep (StemCell, \#07801) gradient separation, according to manufacturer's instructions, within an hour of collection in $\mathrm{K}_{2}$-EDTA coated vacutainer tubes (BD, \#366643). Donor PBMCs were immediately injected into recipient mice. A subsample of PBMCs was retained for DNA isolation and flow cytometric analysis. Serum was obtained by centrifugation of blood (15 min at $1300 \mathrm{x} \mathrm{g}$ ) collected in uncoated vacutainers $(\mathrm{BD}, \# 367820)$ and frozen at $-80^{\circ} \mathrm{C}$ prior to analysis. 


\section{Animals}

Animal work was approved by the Animal Care Committee of the University of British Columbia, under regulation of the Canadian Council of Animal Care, under protocols A17-0266 and A17-0184. Adult male NSG (NOD.Cg-Prkdc $c^{\text {scid }} I l 2 \mathrm{rg}^{t m 1 W j l} / \mathrm{SzJ}, \quad J A X \quad$ \#005557), NSG-SGM3 (NOD.Cg-

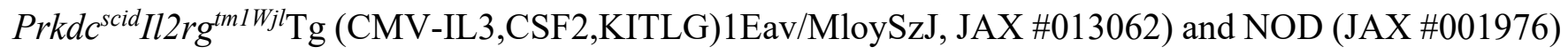
mice, originally sourced from the Jackson Laboratory, began experiments at $6-14$ weeks old. In preliminary experiments, we observed a greater incidence of graft-versus-host disease (GvHD) and reduced EAE symptom incidence in female NSG mice compared to male NSG mice engrafted with the same donor PBMC (data not shown, DNS), and therefore male NSG mice were used as recipients for this study. Moreover, NSG-SGM3 mice, which differ from the NSG by transgenic expression of human hematopoietic cytokines ${ }^{45,77}$, exhibited similar incidence of EAE and GvHD symptoms as NSG mice engrafted with the same donor PBMC (DNS) and were thus used interchangeably when randomized to recipient groups. Mice were bred in three facilities in Vancouver, British Columbia (BC Cancer Animal Resource Centre, Centre for Disease Modelling, and Modified Barrier Facility) to minimize facilityspecific outcomes and housed in the same specific pathogen-free facility at the University of British Columbia for the duration of experiments (Modified Barrier Facility). Mice were housed in groups up to five animals per cage on corn cob bedding (Bed-o'Cobs, The Andersons) and fed ad libitum with PicoLab Rodent Diet 20 (\#5053) standard irradiated chow with free access to autoclaved acidified water ( $\mathrm{pH} 3-$ 4). Housing rooms were set at $22-25^{\circ} \mathrm{C}$ with a humidity range of $50-70 \%$. All NSG cages were kept on the same designated immunocompromised rack on a 14.5 - 9.5-hour light-dark cycle with sunrise at 5:30 am, sunset at 8:00 pm.

\section{Humanization and EAE induction}

NSG mice were engrafted with $5 \times 10^{6}$ donor PBMCs each (or blank phosphate buffered saline (PBS) for un-engrafted controls) by intravenous tail vein injection. Twelve to twenty mice per donor were randomly assigned to recipient groups based on PBMC yield and available stock on the day of blood donation. Following a three-week reconstitution period, circulating human $\mathrm{CD}^{+} 5^{+}$cell repopulation was confirmed by saphenous vein blood sampling and flow cytometric analysis. HuPBMC mice, as well as un-engrafted NSG and NOD control mice for some experiments, were actively induced with EAE on day 0 by subcutaneous injection of a $100 \mu \mathrm{L}$ total volume containing $200 \mu \mathrm{g} \mathrm{MOG}_{35-55}$ peptide (GenScript), $100 \mu \mathrm{g}$ recombinant human MOG (rhMOG (120 $_{1-2}$ prepared in-house) and $400 \mu \mathrm{g}$ desiccated M. Tuberculosis 
H37Ra (DIFCO, \#DF3114-338) emulsified in incomplete Freund's adjuvant (DIFCO, \#DF0639-60-6). On days 0 and 2 post-immunization, mice received an intraperitoneal injection of $200 \mathrm{ng}$ pertussis toxin (List Biological Laboratories, \#1794). The mice were monitored and scored daily for EAE symptoms. Clinical EAE scoring was based on the following 5-point scale: 0, no overt signs of disease; 0.5 , partially limp tail; 1, limp tail; 1.5 limp tail and hind limb weakness; 2, loss of coordinated movements; 2.5, one hind limb paralyzed; 3 , both hind limbs paralyzed; 3.5, hind limbs paralyzed and weakness in forelimbs; 4, forelimbs paralyzed; 5, moribund state or death by EAE. Clinical outcome assessors of HuPBMC EAE mice were blinded to the viral serostatus of the blood donors. Onset was defined by the occurrence of tail paralysis (score 0.5 or higher) for two consecutive days. Cumulative EAE scores were calculated by summing daily clinical scores from the day of onset until endpoint. Mice with motor impairments and signs of illness were provided supportive care, including administration of subcutaneous fluids and cage heating, and provisions of wet food and nutritional gel. Humane endpoint was defined by an EAE score of 4 or greater, or a clinical health score of 4 or greater, as defined by the Animal Care Committee based on body condition, weight loss and signs of pain. Due to intragroup variability in EAE symptom onset, and ongoing GvHD and wasting following the resolution of EAE symptoms, HuPBMC EAE mice could not be maintained longer than approximately ten days post-symptom onset without succumbing to illness. Recipient cohorts were treated with the same experimental interventions for humanization and EAE induction and assigned at random to different endpoint analyses.

\section{Recombinant human MOG protein}

The extracellular domain of recombinant human myelin oligodendrocyte protein ( rhMOG $\left._{1-120}\right)$ was expressed from an Escherichia coli (BL21) vector (pQE-30) obtained from Drs. Christopher Linington and Nancy Ruddle ${ }^{78,79}$, and the protocol was modified from that of Dr. Jennifer Gommerman. The vector expresses a $15.8 \mathrm{kDa}$ His-tagged rhMOG protein under the control of a lac operon. Following isopropyl B-D-1-thiogalactopyranoside (IPTG) induction, the cells were lysed to release the protein product from inclusion bodies. The protein was subsequently purified using a $\mathrm{Ni}^{2+}$-His-bind resin column (5 mL HisTrap FF, Cytiva, \#17525501) and the protein fractions were analyzed by SDS-PAGE gel electrophoresis and stained with Coomassie blue. The fractions containing sufficiently pure protein of the correct molecular weight were pooled and diluted to a protein concentration of $<0.5 \mathrm{mg} / \mathrm{mL}$ in preparation for partial refolding in cellulose dialysis tubing (6-8 $\mathrm{kDa}$ molecular weight cut-off, MWCO). The refolded protein product was concentrated by centrifugation in $3 \mathrm{~K}$ MWCO Amicon tubes (EMD 
Millipore, \#UFC900324) until a final concentration of at least $4 \mathrm{mg} / \mathrm{mL}$ was reached. The final concentration was determined using a Nanodrop Lite Spectrophotometer (Thermo Scientific, firmware version 1.02) $(\mathrm{MW}=15.5 \mathrm{kDa}, \mathrm{e} / 1000=12.09)$. Protein samples were aliquoted, and flash frozen in liquid nitrogen prior to storage at $-80^{\circ} \mathrm{C}$. The purified and concentrated rhMOG protein was confirmed to elicit an encephalitogenic response by induction of EAE symptoms in C57B1/6 mice.

\section{Tissue collection}

Mice were euthanized at endpoint by isoflurane overdose. Blood was collected by cardiac puncture, followed by perfusion with $20 \mathrm{~mL}$ of sterile PBS for collection of CNS tissues. Brains, spinal cords, and spleens were dissected whole and kept in cold sterile PBS or in 10\% neutral buffered formalin (NBF) for further processing. Spinal cords were straightened, placed onto filter paper, and submerged in NBF for histological analyses. The presence of intact emulsion was confirmed by examining the skin at the injection site. Serum was extracted from untreated blood samples by centrifugation (13 min at 8000 $\mathrm{rpm}$ ) and stored at $-80^{\circ} \mathrm{C}$ prior to analysis. Tissues from animals in each recipient cohort were included for analysis regardless of the occurrence of clinically visible EAE symptoms to account for differences in incidence and severity among donor groups.

\section{Histological analysis}

\section{Immunohistochemistry}

Perfused, intact organs collected for analysis of cellular infiltration by immunohistochemistry (IHC) were stored in 10\% NBF for 2 hours at room temperature (RT). At 2 hours, brains were halved by sagittal division and incubated for another 2 hours along with the spinal cords (4 hours total in NBF at RT). CNS organs were washed in cold PBS for 1 hour at $4^{\circ} \mathrm{C}$ to remove remaining NBF, then placed in $15 \%$ sucrose solution overnight at $4{ }^{\circ} \mathrm{C}$ for cryoprotection. Organs were then placed in a $30 \%$ sucrose solution overnight at $4{ }^{\circ} \mathrm{C}$, then placed overnight at $4^{\circ} \mathrm{C}$ in a $25 \%$ sucrose solution containing $50 \%$ optimal cutting temperature compound (OCT, VWR Clear Frozen Section Compound, \#CA95057-838). Cryoprotected organs were segmented in the case of spinal cords, and oriented in cryomolds containing OCT medium and frozen on a partially submerged aluminum block equilibrated in liquid nitrogen, then stored at $-80^{\circ} \mathrm{C}$ for sectioning. Brain and spinal cord tissues were cut at $-19^{\circ} \mathrm{C}$ into $12-\mu \mathrm{m}$ sagittal and coronal sections, respectively, using a Shandon Cryotome ${ }^{\circledR}$ FSE (Thermo), and placed onto Superfrost 
Plus microscope slides (Fisher Scientific, \#12-550-15). Sections were taken at least 30- $\mu \mathrm{m}$ apart and obtained from one of either brain hemispheres, or from four equally distant points along the length of the spinal cord. Sections were rehydrated in PBS for 10 min at RT, followed by blocking in 3\% mouse serum in PBS overnight at $4^{\circ} \mathrm{C}$. Sections were thrice washed in PBS (5 min per wash) and incubated with rabbit anti-human CD8 primary antibody (Table M1) diluted 1:200 in 2\% mouse serum in PBS for 2 hours at $4^{\circ} \mathrm{C}$. A rat IgG isotype primary (Abcam, \#ab27478) was used to confirm the specificity of the secondary antibody binding to anti-human CD8. Sections were then thrice washed and incubated with conjugated donkey anti-rabbit IgG secondary antibody diluted 1:600 in 2\% mouse serum in PBS for 2 hours at $4^{\circ} \mathrm{C}$. Sections were thrice washed with PBS then incubated for $20 \mathrm{~min}$ at RT in PBS containing $0.2 \%$ Triton X100 (PBT solution). CNS sections were incubated $20 \mathrm{~min}$ at RT in a PBT master mix containing FluoroMyelin ${ }^{\mathrm{TM}}$ Green, NeuroTrace ${ }^{\mathrm{TM}}$ 530/615 and diamidino-2-phenylindole (DAPI) (BrainStain ${ }^{\mathrm{TM}}$ Imaging Kit, Invitrogen \#B34650). Sections were then thrice washed in PBT (15 min per wash) to remove excess stain. Slides were mounted with ProLong ${ }^{\text {TM }}$ Diamond Antifade Mountant medium (Invitrogen, \# P36961), sealed, allowed to cure for 24 hours at room temperature, and then stored at $4^{\circ} \mathrm{C}$ until imaged.

\section{Demyelination}

Perfused, intact spinal cords collected for analysis of myelination were stored in $10 \% \mathrm{NBF}$ overnight at RT, then moved to $70 \%$ ethanol and sent to Wax-it Histology Services Inc. for paraffin embedding. To quantify myelination throughout the organ, a total of $6-9$ consecutive $10-\mu \mathrm{m}$ coronal sections were taken from of $4-6$ equally distanced regions along the length of the spinal cord using a Shandon Finesse 325 microtome (Thermo Scientific). Sections were mounted on Superfrost Plus microscope slides (Fisher Scientific, \#12-550-15), dried at $37^{\circ} \mathrm{C}$ for one hour, and then air dried overnight at RT. Sections were washed in 3 changes of xylene for 10 minutes each, then treated in 3 changes of absolute ethanol for 3 minutes each and hydrated in 95\% ethanol for 5 minutes. Slides were incubated in eriochrome cyanine R (EC, Sigma-Aldrich, \#3564-18-9) staining solution $(0.22 \% \mathrm{w} / \mathrm{v}$ ferric chloride, $0.5 \% \mathrm{v} / \mathrm{v}$ sulfuric acid and $0.2 \% \mathrm{w} / \mathrm{v}$ eriochrome cyanine R CI 43820) for 20 minutes, run under tap water for 30 seconds, and incubated in differentiating solution $(5.6 \% \mathrm{w} / \mathrm{v}$ ferric chloride) for $5-10$ minutes until only the white matter retained the stain. Slides were washed under running tap water for 5 minutes, then dehydrated in 3 changes of $100 \%$ ethanol for 30 seconds each (with agitation) and cleared in 3 changes of xylene for 30 seconds each (with agitation). Coverslips were mounted with VectaMount Permanent Mounting Medium (Vector Laboratories, \#H-5000). 


\section{Imaging and analysis}

Histology sections were imaged using a Zeiss Axio Observer 7 epi-fluorescent microscope outfitted with a motorized stage (x, y, z mobility) and five LED channels. Whole organ immunofluorescent sections were imaged at x20/0.65 NA air objective using an Axiocam 702 mono CMOS camera. Isotype staining was used to set LED voltages and exposures across slides per imaging experiment. Immunofluorescent images are shown as an extended depth of focus of Z-stacks (3 stacks of $1.2 \mu \mathrm{m}$ each). Brightfield images of EC-stained spinal cord sections were acquired at 10X/0.3 NA magnification using an Axiocam 105 colour CMOS camera. Stitching and subsequent analysis of images was performed using Zen 2.6 Pro (blue edition, Zeiss). For EC sections, single RBG images were saved as JPEG files and quantitative analysis of staining was performed using ImageJ 1.53c (NIH). Default color thresholding method was used to first select the area of stained myelin and then the total area of the spinal cord. Hue, saturation, and brightness thresholds were set based on fully myelinated NSG control sections and applied across all other sections. The Area measurement function was used to acquire the area of the selected regions in $\mu \mathrm{m}^{2}$, relative to a $200-\mu \mathrm{m}$ scale bar. Myelination was expressed as fraction of myelin-stained area of total area of the spinal cord section. Replicate sections (6-9 consecutive sections per region) were averaged to generate $4-6$ regional myelination indices per spinal cord.

\section{Flow cytometric analysis}

\section{Sample processing}

Brains, spinal cords, and spleens were kept in sterile PBS on ice, then processed into single cell suspensions by passing the tissue through a $70-\mu \mathrm{m}$ cell strainer with a syringe insert. Splenocyte suspensions were incubated in red blood cell lysis buffer $\left(150 \mathrm{mM} \mathrm{NH} 4 \mathrm{Cl}, 10 \mathrm{mM} \mathrm{KHCO} 3,0.1 \mathrm{mM} \mathrm{Na}_{2}-\right.$ EDTA) for $10 \mathrm{~min}$ on ice. Brain and spinal cord samples specifically processed for the detection of intracellular MBP within phagocytic cells were predigested with $0.5 \mathrm{mg} / \mathrm{mL}$ Collagenase/Dispase ${ }^{\circledR}$ (Roche, \#11097113001), $0.02 \mathrm{mg} / \mathrm{mL}$ DNase I (Sigma-Aldrich, \#D5025) and 2\% FBS in $10 \mathrm{~mL}$ RPMI per sample for 45 min shaking at $180 \mathrm{rpm}$ and $37^{\circ} \mathrm{C}$. CNS cells were further isolated by resuspension in $40 \%$ isotonic Percoll ${ }^{\mathrm{TM}}$ solution (Cytiva, \#17089101) and centrifugation (15 min at $1400 \mathrm{rpm}$ ) to remove lipid debris. Samples analyzed for cytokine expression were incubated at $37^{\circ} \mathrm{C}$ for 4 hours at $1-2 \times 10^{6}$ splenocytes or total isolated CNS cells per $200 \mu \mathrm{L}$ of stimulation media, containing $10 \% \mathrm{FBS}, 10 \mathrm{ng} / \mathrm{mL}$ phorbol 12-myristate 13-acetate (PMA, Sigma-Aldrich, \#P1585), 500 ng/mL ionomycin (Thermo Fisher, 
\#I24222) and $1 \mu \mathrm{L} / \mathrm{mL}$ GolgiPlug ${ }^{\mathrm{TM}}$ Protein Transport Inhibitor (containing Brefeldin A, BD Biosciences, \#555029). Cell suspensions were washed between each step with sterile PBS containing 2\% FBS (FACS buffer).

\section{Cell sorting and co-culture}

For interspecies antigen presentation assays, splenocytes were isolated from $\mathrm{EBV}^{+} \mathrm{HD}$ PBMCengrafted male NSG mice at 4 weeks post-injection, as described above. Splenocytes were combined from all mice, stained with fluorochrome-labelled anti-mCD45 and anti-hCD8 antibodies (Table M1), and positively selected using a BD Influx ${ }^{\mathrm{TM}}$ cell sorter. Sorted cells were resuspended to $4 \times 10^{4} \mathrm{mCD} 45^{+}$cells with $4 \times 10^{5} \mathrm{hCD}^{+}$cells (1:10 ratio) per well in $200 \mu \mathrm{L}$ complete culture medium (RPMI-1640 plus FBS, L-glutamine, penicillin/streptomycin, MEM NEAA, sodium pyruvate, HEPES, $\beta$-mercaptoethanol), supplemented with or without $20 \mu \mathrm{g} / \mathrm{mL}$ rhMOG protein, and incubated for 65 hours at $37^{\circ} \mathrm{C}$. Cells were then refreshed with pre-warmed culture medium (same respective rhMOG treatments) containing 1 $\mu \mathrm{L} / \mathrm{mL}$ GolgiPlug ${ }^{\mathrm{TM}}$ Protein Transport Inhibitor and incubated for another 5 hours at $37^{\circ} \mathrm{C}$. Following 70 $\mathrm{hr}$ total incubation, cells were washed with serum-free PBS and stained for flow cytometric analysis as described below.

\section{Antibody staining and analysis}

Cells were stained with $1 \mathrm{X}$ eBioscience ${ }^{\mathrm{TM}}$ Fixable Viability Dye eFluor ${ }^{\mathrm{TM}} 506$ (Thermo Fisher, 65-0866-14) for $20 \mathrm{~min}$ at $4^{\circ} \mathrm{C}$ in serum-free PBS. Cells were then washed in FACS buffer, and preincubated with human and mouse Fc block (Table M1) in FACS buffer for 10 minutes at RT. Cells were washed again and incubated with fluorochrome-labelled antibodies specific to extracellular makers (Table M1) in FACS buffer for 30 minutes at $4^{\circ} \mathrm{C}$. Cells were washed and treated with transcription factor fixation and permeabilization reagent (Thermo Fisher, \#00-5521-00) for $30 \mathrm{~min}$ at $4^{\circ} \mathrm{C}$, followed by a wash with permeabilization buffer (Thermo Fisher, \#00-8333-56). Cells were incubated with fluorochrome-labelled antibodies specific to intracellular makers (Table M2) in permeabilization buffer for 30 min at RT. Cells were washed with permeabilization and FACS buffer and resuspended in FACS buffer with $2 \mathrm{mM}$ EDTA for acquisition. Frozen human PBMC samples were stained as detailed above for use as titration, compensation, and gating controls for all experiments. Stained cell suspensions were acquired on an Attune NxT flow cytometer (Thermo Fisher) and analyzed using FlowJo ${ }^{\mathrm{TM}}$ v10.8 Software (BD Life Sciences). 


\section{Serology}

Endogenous antibodies to EBV, CMV and rhMOG were detected using indirect enzyme-linked immunosorbent assays (ELISA). Nunc Maxisorp 96-well microtiter ELISA plates (Thermo Fisher, \#439454) were coated overnight at $4^{\circ} \mathrm{C}$ with $1 \mu \mathrm{g} / \mathrm{well}$ of the peptide or protein of interest (Table M3, produced by ScenicBio) in $0.05 \mathrm{M}$ carbonate buffer. For EBV EBNA-1 and CMV, epitope peptides 1 and 2 were mixed prior to well coating. The following day, the plates were washed thrice with PBS and wash buffer (PBS $+0.05 \%$ Tween-20), followed by a two-hour blocking step at RT using wash buffer $+3 \%$ bovine serum albumin. Plates were washed again, then incubated with serum samples serially diluted in blocking buffer to generate duplicate 6-point curves (1:100 - 1:5000 for human donor serum and 1:50 1:2500 for mouse serum). After a two-hour RT incubation with serum dilutions, the plates were washed, then incubated with HRP-labelled anti-human IgG antibody (Table M1) diluted 1:3000 in blocking buffer, or HRP-labelled anti-human IgM diluted 1:4000, for 1 hour at $37^{\circ} \mathrm{C}$. The plates were then washed with PBS prior to the addition of $100 \mu \mathrm{L} /$ well TMB substrate (BD Biosciences, \#555214). Fifteen minutes after the addition of substrate, $100 \mu \mathrm{L}$ stop solution ( $2 \mathrm{~N}$ sulfuric acid) was added to each well. The plates were read at $450 \mathrm{~nm}$ on a VarioSkan Plate Reader (Thermo Fisher) within 10 min of adding stop solution. Donor serum at 1:1000 dilution was used to determine seropositivity to EBV and CMV antigens. The lower limit of detection for positive IgG and IgM values was set based on the level of nonspecific background signal in negative control samples (full reaction minus antigen and/or serum). Donor serum vitamin D levels were quantified using the 25-OH Vitamin D ELISA assay test kit, according to the manufacturer's instructions (Eagle Biosciences, \#VID31-K01).

\section{EBV viral load}

Genomic DNA was isolated from a maximum of $4 \times 10^{6}$ donor PBMCs or mouse splenocytes per sample using the PureLink ${ }^{\mathrm{TM}}$ Genomic DNA Minikit (Invitrogen, \#K1820), according to the manufacturer's instructions, quantified using a Nanodrop Lite Spectrophotometer (Thermo Scientific, firmware version 1.02 ), and stored at $-80^{\circ} \mathrm{C}$. A $B A L F 5$ viral DNA polymerase gene qPCR protocol adapted from Kimura et al. ${ }^{(3)}$ was used to measure EBV load in DNA samples. The forward and reverse primer and fluorogenic probe sequences are listed in Table M4 (produced by Integrated DNA Technologies), along with the BALF5 gene fragment sequence used for standard curve generation. qPCR reactions comprised $300 \mathrm{ng}$ genomic DNA, $0.4 \mu \mathrm{M}$ each primer, $0.2 \mu \mathrm{M}$ probe, and 1X QuantiNova Probe PCR master mix (Qiagen, \#208256). An $\mathrm{EBV}^{+}$B95-8 cell line extract (100 ng per reaction) was used as a 
positive control for EBV detection. Blank water was used in negative control reactions. An 8-point standard curve was generated with 1 to $10^{7}$ BALF5 gBlock copies per reaction. Reactions were made up in Mx3000P 96-well plates (Agilent Technologies, \#401333) and data were acquired using a CFX96 RealTime System C1000 Thermal Cycler (Bio-Rad) and CFX manager 3.1 software for HEX detection. The cycler parameters were set according to the Qiagen QuantiNova Probe PCR protocol -2 min at $95^{\circ} \mathrm{C}$ to activate DNA polymerase then 45 repeats of $5 \mathrm{sec}$ at $95^{\circ} \mathrm{C}$ and $5 \mathrm{sec}$ at $60^{\circ} \mathrm{C}$. Sample copies per reaction were determined by interpolation of the standard curve using triplicate-averaged reaction threshold values $\left(\mathrm{C}_{\mathrm{T}}\right)$, which were then used to calculate viral load. The lower limit of detection was determined by interpolating the $\mathrm{C}_{\mathrm{T}}$ value for the lowest detectable standard point per plate and was normally $\sim 30 \mathrm{EBV}$ copies/ $\mu \mathrm{g}$ DNA.

\section{Statistical analyses}

Data were collated using Microsoft Excel, then graphed and statistically analyzed using GraphPad Prism software 9.2.0 (GraphPad Software Inc.). Figure panels were composed in Adobe Illustrator V24.3. Most graphs present group means with standard error (SEM) unless otherwise stated in the figure legend. No statistical methods were used to predetermine sample sizes, as donor PBMC yield limited recipient cohort size. No inclusion or exclusion criteria were used for analyses and groups include all mice from the cohort regardless of the incidence of clinical EAE symptoms, unless otherwise stated. Two normally distributed groups of data were analyzed by two-tailed, unpaired t-test with Welch's correction. For three or more groups, normally distributed data were analyzed by ordinary one-way analysis of variance (ANOVA) with Tukey's multiple comparisons test or Brown-Forsythe and Welch ANOVA with Dunnett's T3 multiple comparisons test. If group data did not pass the Kolmogorov-Smirnov normality test (or Shapiro-Wilk test when group $\mathrm{N}$ too small to compute KS distance), a nonparametric MannWhitney test or Kruskal-Wallis with Dunn's multiple comparisons test was used. A Log-rank (MantelCox) test was used for incidence curve analysis, simple linear regression analysis for cell count correlations, and ordinary two-way ANOVA for group comparisons with two variables (i.e., EAE scores over time and ELISA absorbance readings with serum dilution), where the column factor $\mathrm{p}$ value is reported. Specific statistical tests used for each assay are noted in the figure legends, along with the number of animals or replicates per group. Significance is indicated by asterisks: $* * * * p<0.0001, * * * p<0.001$, $* * p<0.01$, and $* p<0.05$. The data that support the findings of this study are available from the corresponding author upon reasonable request. 
Table M1 - Antibodies for extracellular targets.

\begin{tabular}{|c|c|c|c|c|c|}
\hline Target antigen & Clone & Species reactivity & Application & Source & Identifier \\
\hline CD3 & OKT3 & Human & Flow cytometry & Thermo Fisher & $56-0037-42$ \\
\hline CD4 & RPA-T4 & Human & Flow cytometry & BD Biosciences & 555347 \\
\hline $\mathrm{CD} 8$ & SP16 & Human & IHC-F & Thermo Fisher & MA5-14548 \\
\hline CD8 & RPA-T8 & Human & Flow cytometry & Thermo Fisher & $11-0088-42$ \\
\hline CD8 & RPA-T8 & Human & Flow cytometry & BD Biosciences & 563821 \\
\hline CD11b & $\mathrm{M} 1 / 70$ & Mouse & Flow cytometry & Thermo Fisher & $17-0112-82$ \\
\hline CD11c & N418 & Mouse & Flow cytometry & Thermo Fisher & $11-0114-85$ \\
\hline CD14 & 63D3 & Human & Flow cytometry & BioLegend & 367142 \\
\hline CD14 & $61 \mathrm{D} 3$ & Human & Flow cytometry & Thermo Fisher & $11-0149-42$ \\
\hline CD19 & HIB19 & Human & Flow cytometry & Thermo Fisher & $47-0199-42$ \\
\hline CD20 & $2 \mathrm{H} 7$ & Human & Flow cytometry & BioLegend & 302328 \\
\hline CD21 & HB5 & Human & Flow cytometry & Thermo Fisher & $12-0219-42$ \\
\hline CD25 & CD25-4E3 & Human & Flow cytometry & Thermo Fisher & $11-0257-42$ \\
\hline CD25 & BC96 & Human & Flow cytometry & Thermo Fisher & $45-0259-42$ \\
\hline $\mathrm{CD} 27$ & LG.3A10 & Human & Flow cytometry & BioLegend & 124216 \\
\hline CD40 & $3 / 23$ & Mouse & Flow cytometry & Thermo Fisher & MA5-17855 \\
\hline CD45 & HI30 & Human & Flow cytometry & Thermo Fisher & MHCD4517 \\
\hline CD45 & HI30 & Human & Flow cytometry & BD Biosciences & 557748 \\
\hline CD45 & $30-\mathrm{F} 11$ & Mouse & Flow cytometry & Thermo Fisher & $45-0451-82$ \\
\hline CD45 & 30-F11 & Mouse & Flow cytometry & Thermo Fisher & $48-0451-82$ \\
\hline CD56 & TULY56 & Human & Flow cytometry & Thermo Fisher & $17-0566-42$ \\
\hline CD68 & $\mathrm{Y1/82 \textrm {A }}$ & Human & Flow cytometry & BioLegend & 333825 \\
\hline CD137 & 4B4-1 & Human & Flow cytometry & BioLegend & 309818 \\
\hline $\mathrm{F} 4 / 80$ & BM8 & Mouse & Flow cytometry & Thermo Fisher & $47-4801-82$ \\
\hline $\begin{array}{c}\text { Fc receptor } \\
(\mathrm{CD} 16 / \mathrm{CD} 32)\end{array}$ & $2.4 \mathrm{G} 2$ & Mouse & Flow cytometry & BD Biosciences & 553142 \\
\hline Fc receptor & Fc1.3216 & Human & Flow cytometry & BD Biosciences & 564220 \\
\hline $\operatorname{IgG}(\gamma$ chain $)$ & Polyclonal & Human & ELISA & Thermo Fisher & $62-8420$ \\
\hline $\operatorname{IgG}(\mathrm{H}+\mathrm{L})$ & Polyclonal & Rabbit & IHC-F & Thermo Fisher & A10043 \\
\hline $\operatorname{IgG} 2 b$ & $\mathrm{~m} 2 \mathrm{~b}-25 \mathrm{G} 4$ & Mouse & Flow cytometry & Thermo Fisher & $11-4220-82$ \\
\hline $\operatorname{IgM}(\mu$ chain $)$ & Polyclonal & Human & ELISA & Thermo Fisher & A18841 \\
\hline
\end{tabular}


Table M2 - Antibodies for intracellular targets.

\begin{tabular}{cccccc}
\hline Target antigen & Clone & Species reactivity & Application & Source & Identifier \\
\hline FOXP3 & 236A/E7 & Human & Flow cytometry & Thermo Fisher & $17-4777-42$ \\
\hline Granzyme B & QA16A02 & Human & Flow cytometry & BioLegend & 372214 \\
\hline IFN $\gamma$ & 4S.B3 & Human & Flow cytometry & Thermo Fisher & $48-7319-42$ \\
\hline IL-17A & eBio64DEC17 & Human & Flow cytometry & Thermo Fisher & $25-7179-42$ \\
\hline MBP & MBP101 & Mouse & Flow cytometry & Abcam & ab62631 \\
\hline
\end{tabular}

Table M3 - Antigen sequences for endogenous antibody detection by ELISA.

\begin{tabular}{ll}
\hline \multicolumn{1}{c}{ Antigen } & \multicolumn{1}{c}{ Sequence } \\
\hline \multirow{2}{*}{ EBV VCA p18 ${ }^{80}$} & ASAGTGALASSAPSTAVAQSATPSVSSSISSLRAATSGATAAAAVDTGS \\
& GGGGQPHDTAPRGARKKQ \\
\hline \multirow{2}{*}{ EBV EBNA-1 $^{80}$} & Epitope 1: RSPSSQSSSSGSPPRRPPPGRRPFFHPVG \\
\cline { 2 - 2 } & Epitope 2: DYFEYHQEGGPDGEPDVPPGAIEQGPADDPGEGPSTGPRG \\
\hline \multirow{2}{*}{${\text { rhMOG } 1-120^{78}}^{\text {MASLSRPSLPSCLCSFLLLLLLQVSSSYAGQFRVIGPRHPIRALVGDEVE }}$} \\
& LPCRISPGKNATGMEVGWYRPPFSRVVHLYRNGKDQDGDQAPEYRG \\
& RTELLKDAIGEGKVTLRIRNVRFS \\
\hline \multirow{2}{*}{$\mathrm{CMV}^{81}$} & Epitope 1: CETDDLDEEDTSIYLSPPPVPPVQVVAKRLPRPDTPRT \\
\cline { 2 - 2 } & Epitope 2: KSGTGPQPGSAGMGGAKTPSDAVQNILQKIEKIKNTEE \\
\hline
\end{tabular}

Table M4 - DNA sequences for EBV BALF5 qPCR assay.

\begin{tabular}{ll}
\hline \multicolumn{1}{c}{ Component } & \multicolumn{1}{c}{ Sequence (5' to 3') } \\
\hline Primer P1 $^{30}$ & CGGAAGCCCTCTGGACTTC \\
\hline Primer P2 $^{30}$ & CCCTGTTTATCCGATGGAATG \\
\hline Probe P3 ${ }^{30}$ & /5HEX/TGTACACGC/ZEN/ACGAGAAATGCGCC/3IABkFQ/ \\
\hline & ACC GAG ACC CGG CAG GGG GTC CTG CGG TCG AAG GTG CTG GCC TTG AGG GCG \\
& CTG AGG ACT GCA AAC TCC ACG TCC AGA CCC TGA GGC GCG CTG GCG TAG AAG \\
& TAG GCC TGC TGC CCA AAC ACG TTC ACA CAC ACG CTG GCC CCA TCG GCC TTG \\
BALF5 gene standard & CGC CGG CCC AGT AGC TTG ATG ACG ATG CCA CAT GGC ACC ACA TAC CCC TGT \\
(gBlock) & TTA TCC GAT GGA ATG ACG GCG CAT TTC TCG TGC GTG TAC ACC GTC TCG AGT \\
& ATG TCG TAG ACA TGG AAG TCC AGA GGG CTT CCG TGG GTG TCT GCC TCC GGC \\
& CTT GCC GTG CCC TCT TGG GCA CGC TGG CGC CAC CAC ATG CCC TTT CCA TCC \\
& TCG TCA CCC CCC ACC ACC GTC AGG GAG TCT TGG TAG AAG CAC AGG GGG GGC \\
& TGA GGC CCC CGC ACA TCC ACC ACC CCT GCG GCG CCT GGT GTC TGG AAA CAC \\
\hline
\end{tabular}




\section{REFERENCES}

1. Dendrou, C. A., Fugger, L. \& Friese, M. A. Immunopathology of multiple sclerosis. Nat. Rev. Immunol. 15, 545-558 (2015).

2. Olsson, T., Barcellos, L. F. \& Alfredsson, L. Interactions between genetic, lifestyle and environmental risk factors for multiple sclerosis. Nat. Rev. Neurol. 13, 25-36 (2017).

3. Hjalgrim, H., Friborg, J. \& Melbye, M. The epidemiology of EBV and its association with malignant disease. in Human Herpesviruses: Biology, Therapy, and Immunoprophylaxis (eds. Arvin, A. et al.) (Cambridge University Press, 2007).

4. Chaganti, S. et al. Epstein-Barr virus colonization of tonsillar and peripheral blood B-cell subsets in primary infection and persistence. Blood 113, 6372-6381 (2009).

5. Chen, M.-R. Epstein-Barr Virus, the Immune System, and Associated Diseases. Front. Microbiol. 2, 5 (2011).

6. Dunmire, S. K., Hogquist, K. A. \& Balfour, H. H. Infectious Mononucleosis. Curr. Top. Microbiol. Immunol. 390, 211-240 (2015).

7. Ascherio, A., Munger, K. L. \& Lünemann, J. D. The initiation and prevention of multiple sclerosis. Nat. Rev. Neurol. 8, 602-612 (2012).

8. Thacker, E. L., Mirzaei, F. \& Ascherio, A. Infectious mononucleosis and risk for multiple sclerosis: A meta-analysis. Ann. Neurol. 59, 499-503 (2006).

9. McKay, K. A., Jahanfar, S., Duggan, T., Tkachuk, S. \& Tremlett, H. Factors associated with onset, relapses or progression in multiple sclerosis: A systematic review. NeuroToxicology doi:10.1016/j.neuro.2016.03.020.

10. DeLorenze GN et al. Epstein-barr virus and multiple sclerosis: Evidence of association from a prospective study with long-term follow-up. Arch. Neurol. 63, 839-844 (2006).

11. Ascherio A, Munger KL, Lennette ET, \& et al. Epstein-barr virus antibodies and risk of multiple sclerosis: A prospective study. JAMA 286, 3083-3088 (2001).

12. Bjornevik, K. et al. Longitudinal analysis reveals high prevalence of Epstein-Barr virus associated with multiple sclerosis. Science (2022).

13. Lanz, T. V. et al. Clonally Expanded B Cells in Multiple Sclerosis Bind EBV EBNA1 and GlialCAM. Nature 1-12 (2022) doi:10.1038/s41586-022-04432-7. 
14. Handel, A. E. et al. An Updated Meta-Analysis of Risk of Multiple Sclerosis following Infectious Mononucleosis. PLoS ONE 5, e12496 (2010).

15. Alotaibi, S., Kennedy, J., Tellier, R., Stephens, D. \& Banwell, B. Epstein-Barr virus in pediatric multiple sclerosis. JAMA 291, 1875-1879 (2004).

16. Banwell, B. et al. Clinical features and viral serologies in children with multiple sclerosis: a multinational observational study. Lancet Neurol. 6, 773-781 (2007).

17. Levin, L. I., Munger, K. L., O’Reilly, E. J., Falk, K. I. \& Ascherio, A. Primary Infection with the Epstein-Barr Virus and Risk of Multiple Sclerosis. Ann. Neurol. 67, 824-830 (2010).

18. Lünemann, J. D. et al. EBNA1-specific T cells from patients with multiple sclerosis cross react with myelin antigens and co-produce IFN- $\gamma$ and IL-2. J. Exp. Med. 205, 1763-1773 (2008).

19. Lünemann, J. D. et al. Increased frequency and broadened specificity of latent EBV nuclear antigen1-specific T cells in multiple sclerosis. Brain J. Neurol. 129, 1493-1506 (2006).

20. Jagessar, S. A. et al. The Different Clinical Effects of Anti-BLyS, Anti-APRIL and Anti-CD20 Antibodies Point at a Critical Pathogenic Role of $\gamma$-Herpesvirus Infected B Cells in the Marmoset EAE Model. J. Neuroimmune Pharmacol. 8, 727-738 (2013).

21. Yajima, M. et al. A New Humanized Mouse Model of Epstein-Barr Virus Infection That Reproduces Persistent Infection, Lymphoproliferative Disorder, and Cell-Mediated and Humoral Immune Responses. J. Infect. Dis. 198, 673-682 (2008).

22. Melkus, M. W. et al. Humanized mice mount specific adaptive and innate immune responses to EBV and TSST-1. Nat. Med. 12, 1316-1322 (2006).

23. Lim, W. H., Kireta, S., Russ, G. R. \& Coates, P. T. H. Human plasmacytoid dendritic cells regulate immune responses to Epstein-Barr virus (EBV) infection and delay EBV-related mortality in humanized NOD-SCID mice. Blood 109, 1043-1050 (2007).

24. Islas-Ohlmayer, M. et al. Experimental Infection of NOD/SCID Mice Reconstituted with Human CD34+ Cells with Epstein-Barr Virus. J. Virol. 78, 13891-13900 (2004).

25. Heuts, F. et al. T Cells Modulate Epstein-Barr Virus Latency Phenotypes during Infection of Humanized Mice. J. Virol. 88, 3235-3245 (2014).

26. Kuwana, Y. et al. Epstein-Barr Virus Induces Erosive Arthritis in Humanized Mice. PLoS ONE 6, (2011).

27. Sato, K. et al. A novel animal model of Epstein-Barr virus-associated hemophagocytic lymphohistiocytosis in humanized mice. Blood 117, 5663-5673 (2011). 
28. Rommer, P. S. et al. Relapsing and progressive MS: the sex-specific perspective. Ther. Adv. Neurol. Disord. 13, 1756286420956495 (2020).

29. Mouhieddine, T. H. et al. Risk factors for multiple sclerosis and associations with anti-EBV antibody titers. Clin. Immunol. 158, 59-66 (2015).

30. Kimura, H. et al. Quantitative Analysis of Epstein-Barr Virus Load by Using a Real-Time PCR Assay. J. Clin. Microbiol. 37, 132-136 (1999).

31. Staras, S. A. S. et al. Seroprevalence of Cytomegalovirus Infection in the United States, 1988-1994. Clin. Infect. Dis. 43, 1143-1151 (2006).

32. Lachmann, R. et al. Cytomegalovirus (CMV) seroprevalence in the adult population of Germany. PLOS ONE 13, e0200267 (2018).

33. Baker, D. et al. Autoimmune encephalomyelitis in NOD mice is not initially a progressive multiple sclerosis model. Ann. Clin. Transl. Neurol. 6, 1362-1372 (2019).

34. Furtado, G. C. et al. Swift Entry of Myelin-Specific T Lymphocytes into the Central Nervous System in Spontaneous Autoimmune Encephalomyelitis. J. Immunol. Baltim. Md 1950 181, 46484655 (2008).

35. Hohlfeld, R. \& Steinman, L. T Cell-Transfer Experimental Autoimmune Encephalomyelitis: Pillar of Multiple Sclerosis and Autoimmunity. J. Immunol. 198, 3381-3383 (2017).

36. Yamasaki, R. et al. Differential roles of microglia and monocytes in the inflamed central nervous system. J. Exp. Med. 211, 1533-1549 (2014).

37. Dong, Y.\& Yong, V. W. When encephalitogenic T cells collaborate with microglia in multiple sclerosis. Nat. Rev. Neurol. 15, 704-717 (2019).

38. Gorantla, S., Gendelman, H. E. \& Poluektova, L. Y. Can Humanized Mice Reflect the Complex Pathobiology of HIV-Associated Neurocognitive Disorders? J. Neuroimmune Pharmacol. Off. J. Soc. NeuroImmune Pharmacol. 7, 352-362 (2012).

39. Zhang, J. et al. Human Microglia Extensively Reconstitute in Humanized-BLT Mice With Human Interleukin-34 Transgene and Support HIV-1 Brain Infection. Front. Immunol. 12, 672415 (2021).

40. Morillon, Y. M., Sabzevari, A., Schlom, J. \& Greiner, J. W. The Development of Next-generation PBMC Humanized Mice for Preclinical Investigation of Cancer Immunotherapeutic Agents. Anticancer Res. 40, 5329-5341 (2020).

41. Halkias, J. et al. Conserved and divergent aspects of human T-cell development and migration in humanized mice. Immunol. Cell Biol. 93, 716-726 (2015). 
42. Kroger, C. J. \& Alexander-Miller, M. A. Dose-dependent modulation of CD8 and functional avidity as a result of peptide encounter. Immunology 122, 167-178 (2007).

43. Bar-Or, A. et al. Epstein-Barr Virus in Multiple Sclerosis: Theory and Emerging Immunotherapies. Trends Mol. Med. 26, 296-310 (2020).

44. Lang, J. et al. Replacing mouse BAFF with human BAFF does not improve B-cell maturation in hematopoietic humanized mice. Blood Adv. 1, 2729-2741 (2017).

45. Jangalwe, S., Shultz, L. D., Mathew, A. \& Brehm, M. A. Improved B cell development in humanized NOD-scid IL2R $\gamma$ null mice transgenically expressing human stem cell factor, granulocyte-macrophage colony-stimulating factor and interleukin-3. Immun. Inflamm. Dis. 4, 427440 (2016).

46. Salou, M. et al. Expanded CD8 T-cell sharing between periphery and CNS in multiple sclerosis. Ann. Clin. Transl. Neurol. 2, 609-622 (2015).

47. Babbe, H. et al. Clonal Expansions of Cd8+ T Cells Dominate the T Cell Infiltrate in Active Multiple Sclerosis Lesions as Shown by Micromanipulation and Single Cell Polymerase Chain Reaction. J. Exp. Med. 192, 393-404 (2000).

48. Wagner, C. A., Roqué, P. J., Mileur, T. R., Liggitt, D. \& Goverman, J. M. Myelin-specific CD8+ T cells exacerbate brain inflammation in CNS autoimmunity. J. Clin. Invest. 130, 203-213.

49. Dang, P. T., Bui, Q., D’Souza, C. S. \& Orian, J. M. Modelling MS: Chronic-Relapsing EAE in the NOD/Lt Mouse Strain. in Emerging and Evolving Topics in Multiple Sclerosis Pathogenesis and Treatments (eds. La Flamme, A. C. \& Orian, J. M.) 143-177 (Springer International Publishing, 2015).doi:10.1007/7854_2015_378.

50. Zayoud, M. et al. Subclinical CNS Inflammation as Response to a Myelin Antigen in Humanized Mice. J. Neuroimmune Pharmacol. 8, 1037-1047 (2013).

51. Yin, C. et al. In Vivo Excision of HIV-1 Provirus by saCas9 and Multiplex Single-Guide RNAs in Animal Models. Mol. Ther. 25, 1168-1186 (2017).

52. Ku, C.-C., Besser, J., Abendroth, A., Grose, C. \& Arvin, A. M. Varicella-Zoster Virus Pathogenesis and Immunobiology: New Concepts Emerging from Investigations with the SCIDhu Mouse Model. J. Virol. 79, 2651-2658 (2005).

53. Dittmer, D. et al. Experimental Transmission of Kaposi's Sarcoma-Associated Herpesvirus (Kshv/Hhv-8) to Scid-Hu Thy/Liv Mice. J. Exp. Med. 190, 1857-1868 (1999). 
54. Jodeleit, H. et al. Head-to-head study of oxelumab and adalimumab in a mouse model of ulcerative colitis based on NOD/Scid IL2R $\gamma$ null mice reconstituted with human peripheral blood mononuclear cells. Dis. Model. Mech. 14, dmm046995 (2021).

55. Unterweger, A.-L. et al. NOD/scid IL-2R $\gamma$ null mice reconstituted with peripheral blood mononuclear cells from patients with Crohn's disease reflect the human pathological phenotype. Immun. Inflamm. Dis. 9, 1631-1647 (2021).

56. Pender, M. P. et al. Epstein-Barr virus-specific T cell therapy for progressive multiple sclerosis. JCI Insight 3, e124714.

57. Jagessar, S. A. et al. Antibodies Against Human BLyS and APRIL Attenuate EAE Development in Marmoset Monkeys. J. Neuroimmune Pharmacol. 7, 557-570 (2012).

58. Kappos, L. et al. Atacicept in multiple sclerosis (ATAMS): a randomised, placebo-controlled, double-blind, phase 2 trial. Lancet Neurol. 13, 353-363 (2014).

59. Schmidt, J. et al. Treatment and prevention of experimental autoimmune neuritis with superagonistic CD28-specific monoclonal antibodies. J. Neuroimmunol. 140, 143-152 (2003).

60. Suntharalingam, G. et al. Cytokine storm in a phase 1 trial of the anti-CD28 monoclonal antibody TGN1412. N. Engl. J. Med. 355, 1018-1028 (2006).

61. Casiraghi, C. et al. Gammaherpesvirus Latency Accentuates EAE Pathogenesis: Relevance to Epstein-Barr Virus and Multiple Sclerosis. PLoS Pathog. 8, (2012).

62. Incrocci, R., McCormack, M. \& Swanson-Mungerson, M. Epstein-Barr virus LMP2A increases IL10 production in mitogen-stimulated primary B-cells and B-cell lymphomas. J. Gen. Virol. 94, 1127-1133 (2013).

63. Morandi, E., Jagessar, S. A., Hart, B. A. ‘t \& Gran, B. EBV Infection Empowers Human B Cells for Autoimmunity: Role of Autophagy and Relevance to Multiple Sclerosis. J. Immunol. ji1700178 (2017) doi:10.4049/jimmunol.1700178.

64. Rojas, O. L. et al. Recirculating Intestinal IgA-Producing Cells Regulate Neuroinflammation via IL10. Cell 176, 610-624.e18 (2019).

65. Jain, R. W. \& Yong, V. W. B cells in central nervous system disease: diversity, locations and pathophysiology. Nat. Rev. Immunol. 1-12 (2021) doi:10.1038/s41577-021-00652-6.

66. Pikor, N. B., Prat, A., Bar-Or, A. \& Gommerman, J. L. Meningeal Tertiary Lymphoid Tissues and Multiple Sclerosis: A Gathering Place for Diverse Types of Immune Cells during CNS Autoimmunity. Front. Immunol. 6, (2016). 
67. Serafini, B., Rosicarelli, B., Magliozzi, R., Stigliano, E. \& Aloisi, F. Detection of Ectopic B-cell Follicles with Germinal Centers in the Meninges of Patients with Secondary Progressive Multiple Sclerosis. Brain Pathol. 14, 164-174 (2004).

68. Serafini, B. et al. Dysregulated Epstein-Barr virus infection in the multiple sclerosis brain. J. Exp. Med. 204, 2899-2912 (2007).

69. Pender, M. P. Infection of autoreactive B lymphocytes with EBV, causing chronic autoimmune diseases. Trends Immunol. 24, 584-588 (2003).

70. Laurence, M. \& Benito-León, J. Epstein-Barr virus and multiple sclerosis: Updating Pender's hypothesis. Mult. Scler. Relat. Disord. 16, 8-14 (2017).

71. Lang, H. L. E. et al. A functional and structural basis for TCR cross-reactivity in multiple sclerosis. Nat. Immunol. 3, 940-943 (2002).

72. Long, H. M., Meckiff, B. J. \& Taylor, G. S. The T-cell Response to Epstein-Barr Virus-New Tricks From an Old Dog. Front. Immunol. 10, 2193 (2019).

73. Casiraghi, C., Citlali Márquez, A., Shanina, I. \& Steven Horwitz, M. Latent virus infection upregulates CD40 expression facilitating enhanced autoimmunity in a model of multiple sclerosis. Sci. Rep. 5, 13995 (2015).

74. Mouat, I. C., Morse, Z. J., Shanina, I., Brown, K. L. \& Horwitz, M. S. Latent gammaherpesvirus exacerbates arthritis through modification of age-associated B cells. eLife 10, e67024.

75. Ingelfinger, F. et al. Twin study reveals non-heritable immune perturbations in multiple sclerosis. Nature 1-7 (2022) doi:10.1038/s41586-022-04419-4.

76. Zdimerova, H. et al. Attenuated immune control of Epstein Barr virus in humanized mice is associated with the multiple sclerosis risk factor HLA-DR15. Eur. J. Immunol. (2020) doi:10.1002/eji.202048655.

77. Nicolini, F. E., Cashman, J. D., Hogge, D. E., Humphries, R. K. \& Eaves, C. J. NOD/SCID mice engineered to express human IL-3, GM-CSF and Steel factor constitutively mobilize engrafted human progenitors and compromise human stem cell regeneration. Leukemia 18, 341-347 (2004).

78. Oliver, A. R., Lyon, G. M. \& Ruddle, N. H. Rat and Human Myelin Oligodendrocyte Glycoproteins Induce Experimental Autoimmune Encephalomyelitis by Different Mechanisms in C57BL/6 Mice. J. Immunol. 171, 462-468 (2003).

79. Breithaupt, C. et al. Structural insights into the antigenicity of myelin oligodendrocyte glycoprotein. Proc. Natl. Acad. Sci. U. S. A. 100, 9446-9451 (2003). 
80. Liu, Z. et al. Multilaboratory Assessment of Epstein-Barr Virus Serologic Assays: the Case for Standardization. J. Clin. Microbiol. 57, e01107-19 (2019).

81. Greijer, A. E., Crommert, J. M. G. van de, Stevens, S. J. C. \& Middeldorp, J. M. Molecular FineSpecificity Analysis of Antibody Responses to Human Cytomegalovirus and Design of Novel Synthetic-Peptide-Based Serodiagnostic Assays. J. Clin. Microbiol. (1999) doi:10.1128/JCM.37.1.179-188.1999. 